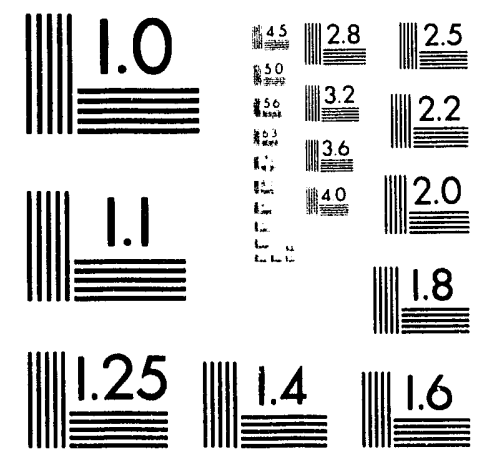



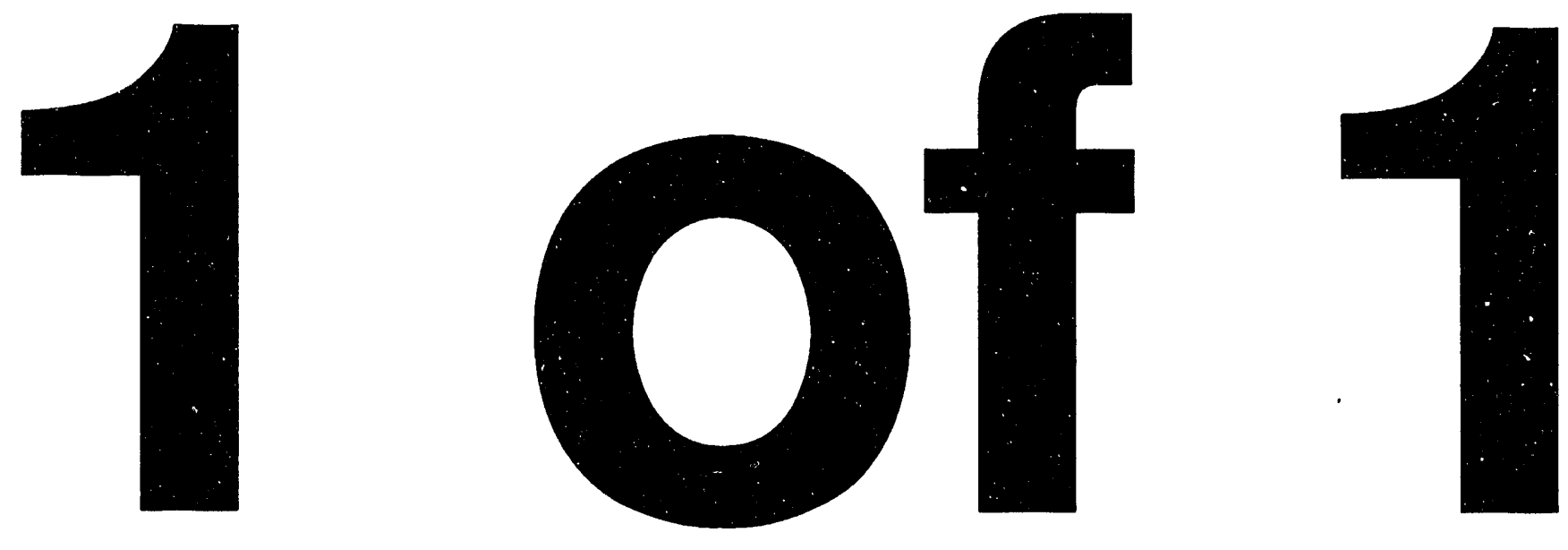


\title{
Test Plan for the Overburden Removal Demonstration
}

\author{
Phil Rice \\ John Skaggs, Sonsub, Inc. \\ Dave Thompson \\ Mike Winberg
}

Published June 1993

\section{Idaho National Engineering Laboratory \\ EG\&G Idaho, Inc. Idaho Falls, Idaho 83415}

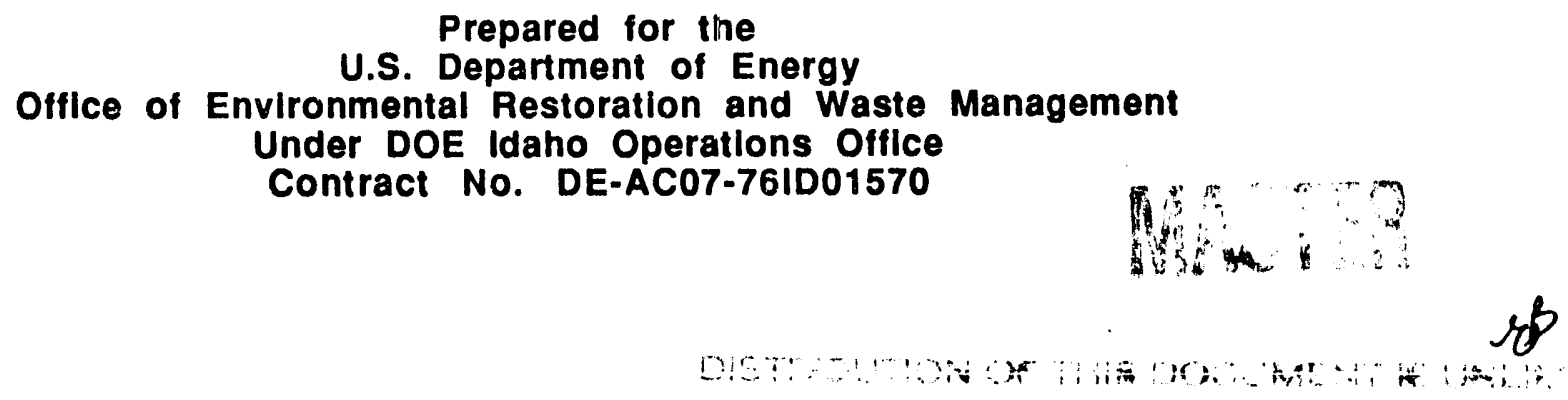


Test Plan for the Overburden Removal Demonstration

EGG-WTD-10716

Prepared by

P. M. Rice, Principle Investigator

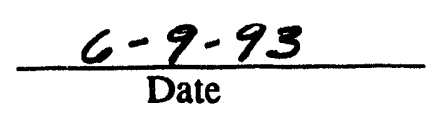

Mechanical Engineering

Reviewed by

Sishlatam

K. A. Baum, Senior Scientist

$\frac{6-10-93}{\text { Date }}$

Environmental Restoration Program

Approved by

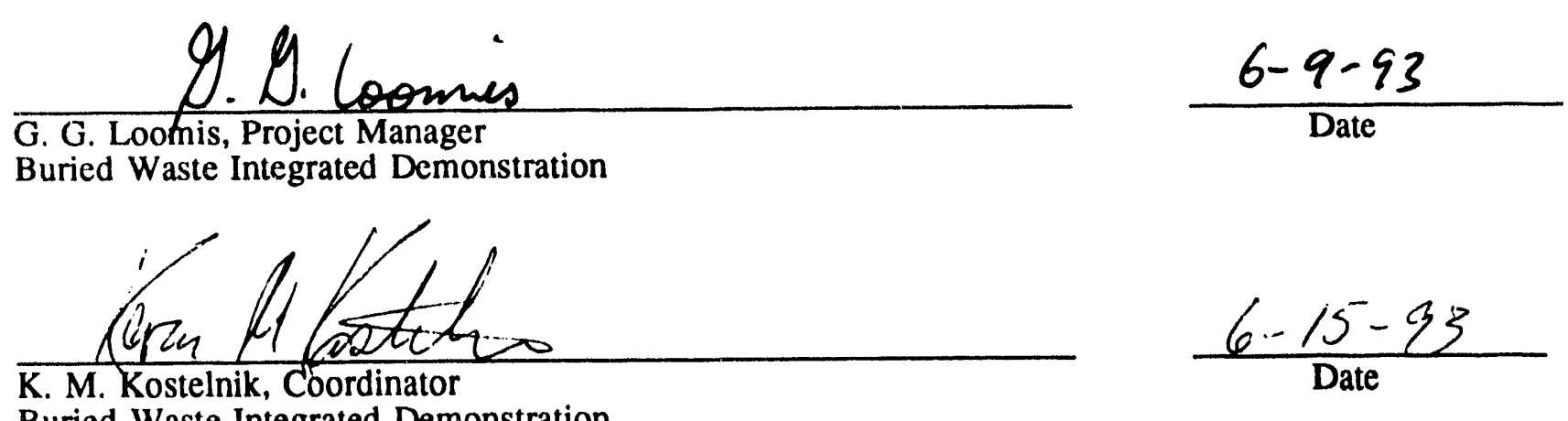




\begin{abstract}
The removal of soil overburdens from contaminated pits and trenches involves using equipment that will remove a small layer of soil from 3 to 6 in. at any time. As a layer of soil is removed, overburden characterization techniques perform surveys to a depth that exceeds each overburden removal layer to ensure that the removed soil will be free of contamination. It is generally expected that no contamination will be found in the soil overburden, which was brought in after the waste was put in place. It is anticipated that some containers in the waste zone have lost their integrity, and the waste leakage from those containers has migrated by gravity downward into the waste zone. To maintain a safe work environment, this method of overburden removal should allow safe preparation of a pit or trench for final remediation.

To demonstrate the soil overburden techniques, the Buried Waste Integrated Demonstration Program has contracted vendor services to provide equipment and techniques demonstrating soil overburden removal technology. The demonstration will include tests that will evaluate equipment performance and techniques for removal of overburden soil, control of contamination spread, and dust control. To evaluate the performance of these techniques, air particulate samples, physical measurements of the excavation soil cuts, maneuverability measurements, and time versus volume (rate) of soit removal data will be collected during removal operations. To provide a medium for sample evaluation, the overburden will be spiked at specific locations and depths with rare earth tracers. This test plan will describe the objectives of the demonstration, data quality objectives, methods to be used to operate the equipment and use the techniques in the test area, and methods to be used in collecting data during the demonstration.
\end{abstract}




\section{SUMMARY}

This test plan is for an overburden soil removal demonstration that is being performed at the Idaho National Engineering Laboratory (INEL) as part of the U.S. Department of Energy (DOE) Office of Technology Development (OTD) Buried Wast" Integrated Demonstration (BWID) Project under the Retrieval Related Technologies Technical Task Plan (TTP) ID 132007. BWID examines promising technologies for demonstration purposes and also develops new technologies for application to DOE sites' waste problems. Additional support for this demonstration is being provided by the Uranium Soils Integrated Demonstration.

The overall objective of this demonstration is to explore the effectiveness of equipment that may ultimately be used (1) remove the overburden soil from transuranic (TRU) waste pits and trenches. The overburden soil is expected to be clean; however, local hot spots may be present in the actual buried waste pits because of past burial practices and metcorological conditions. Therefore, the overburden must be removed in precise, controllable increments. Crucial technical aspects of the overburden nemoval include minimizing dust generation and the potential associated spread of airborne contaminants. It is anticipated that removal procedures will ultimately require both presampling of the excavation region and some screening for hot spots during operations to preclude categorization of contaminated soil as clean soil.

The specific objectives for the test descrited in this plan ane

- Demonstrate that increments of soil can be removed in predetermined and controlled thicknesses and determine the precision and accuracy of the removal equipment and processes.

- Demonstrate the ability of the equipment and processes to control the generation of fugitive dust during removal of the soil and determine the amount of dust generated at the point of excavation

- Demonstrate the ability of the soil removal equipment and techniques to control the spread of contamination by quantifying the amount of tracer material spread during operations.

- Demonstrate and ineasure the maneuverability of the removal equipment and excavate around simulated or real obstacles within the overburden removal area.

- Demonstrate that overburden soil can be removed at rates that would be representative of a production retrieval operation.

The demonstration will be performed at a "cold" test area at the INEL. In 1988, a nonhazardous and nonradioactive (or cold) simulated waste test pit was developed near the Radioactive Waste Management Complex (RWMC). This area, known as the Cold Test Pit is located about $3(x) \mathrm{ft}$ south of the RWMC south fence. The Cold Test Pit concept was conceived when it was realized that to effectively test retrieval, characterization, contamination control, and related technologies, a safe and noncontaminated test bed would be essential. The Cold Test Pit contains materials to represent the forms of the actual waste in a subsurface pit or trench. Furlatermore, the Cold Test Pit is covered by a overburden of soil similar to that of a Subsurface Disposal Area (SDA).

To accomplish the lask, a competitive procurement for a fixed price contract was initiated in fiscal year 1993 to privale industry to solicit proposals for equipment and processes for performing overburden removal. Sonsub, Inc., of Houston, Texas, 
submilted the wioning proposal and was awarded the contract to perform the demonstration at the INEL. in the summer of 1993. The demonstration will include using a standard modem hydraulic excavator with a specially adapted bucket to skim 3, 4, or 6 in. thick layers in 3 ft wide strips from the Cold Test Pit. Bucket adaptations include depth control planes and laser leveling to ensure accurate control of depth oftcut and special features 10 control the generation of dust and spread of contamination.

Work done under the BWID overburden soil removal demonstration project will climinate unknowns in the $(x)$ dy of knowledge about the retrieval options for huried TRU waste at the INEL. This information will be factored into a remedial investigation/feasibility study leading to a final record of decision for disposition of the buried TRU waste. 


\section{CONTENTS}

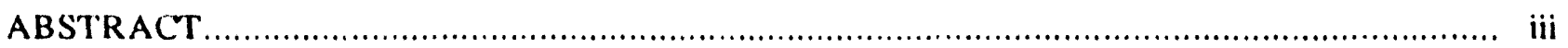

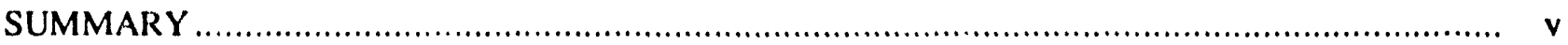

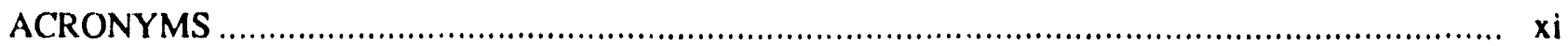

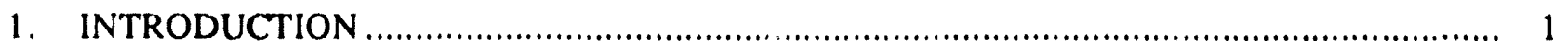

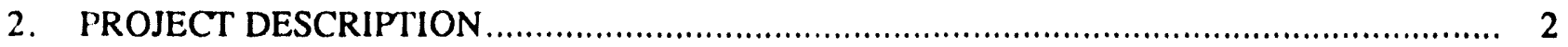

2.1 Background Information..................................................................................... 2

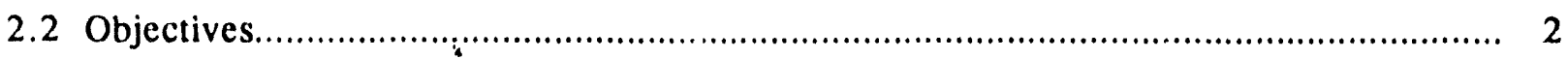

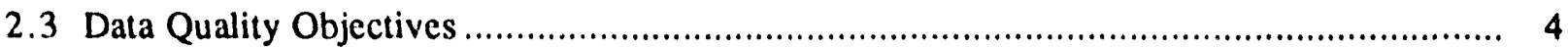

2.3.1 Excavation Depth-of-Cut DQO

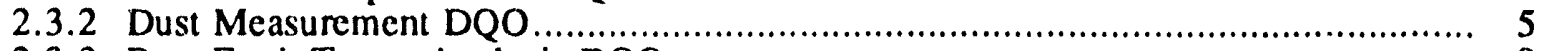

2.3.3 Rare Earth Tracer Analysis DQO .............................................................. 9

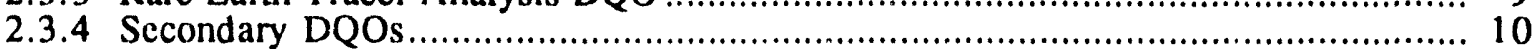

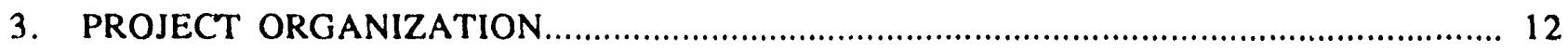

3.1 Buried Waste Integrated Demonstration Program ................................................ 12

3.2 Uranium in Soils Integrated Demonstration Program .............................................. 12

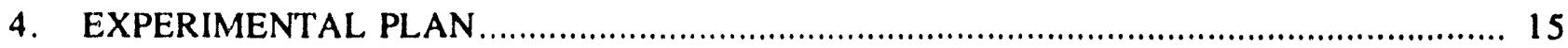

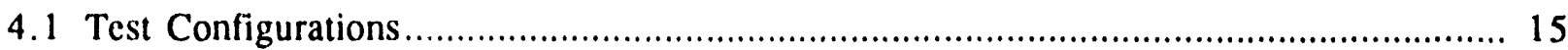

4.1.1 Pit Contour Measurement ............................................................................ 15

4.1.2 Phase I Test - Contamination Spread ....................................................................... 15

4.1.3 Phase II Test-Dust Generation ....................................................................... 15

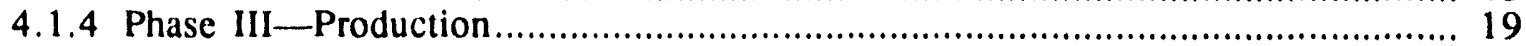

4.1.5 Excavator Track Mapping ................................................................................ 25

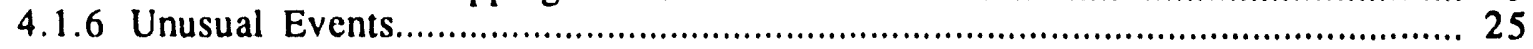

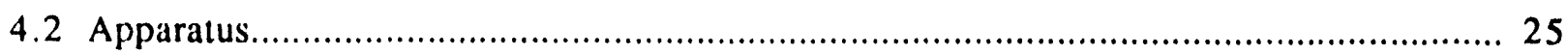

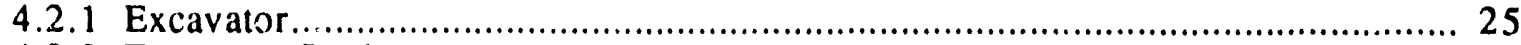

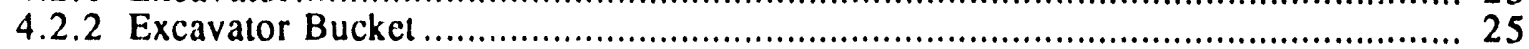

4.2.3 Dust Collection System................................................................................... 28

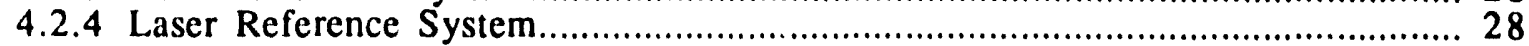

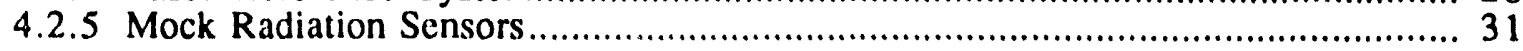

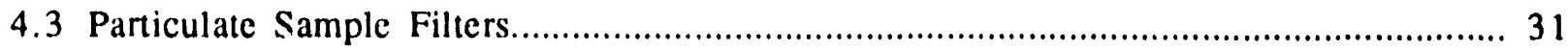

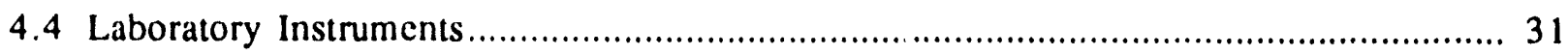

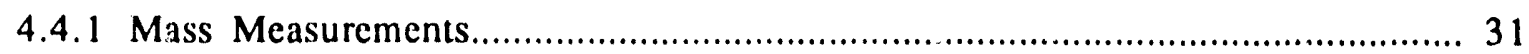

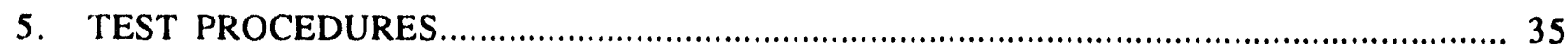

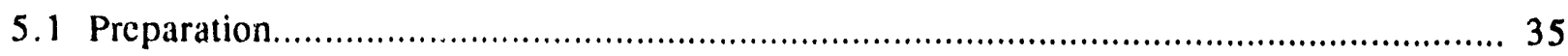




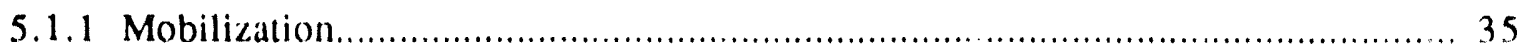

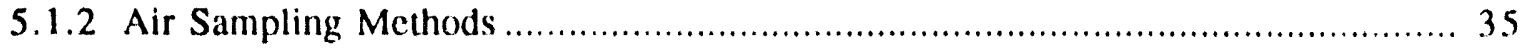

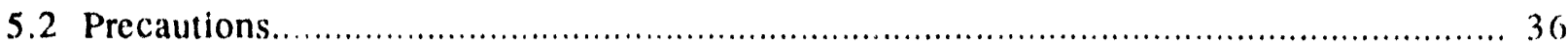

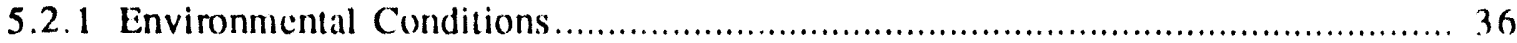

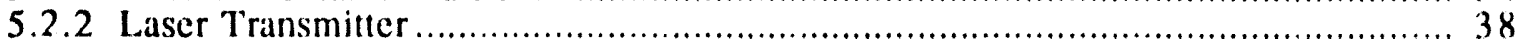

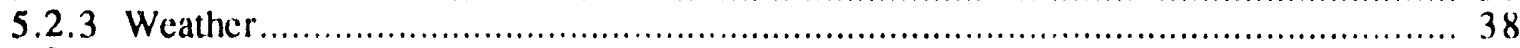

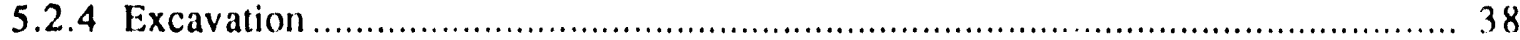

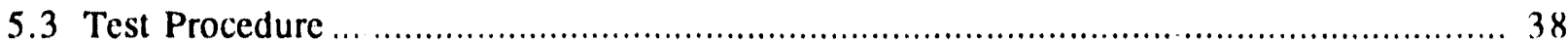

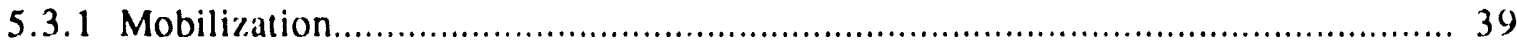

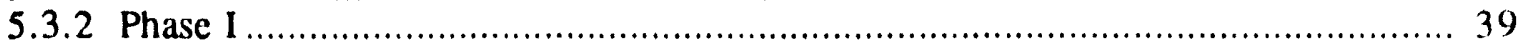

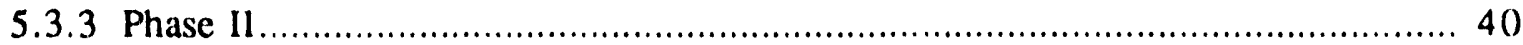

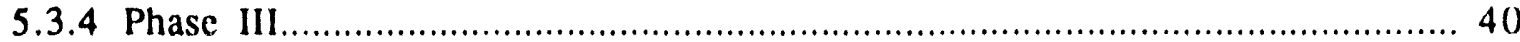

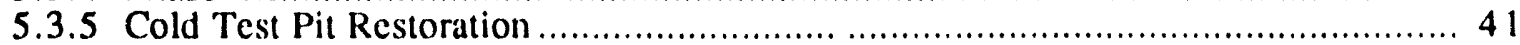

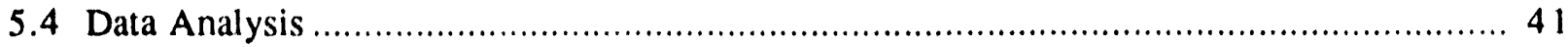

6. SAMPLE CONTROL AND DOCUMENT MANAGEMENT ..................................... 42

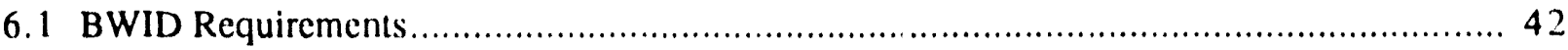

6.1.1 Management of Electronic Data ................................................................ 42

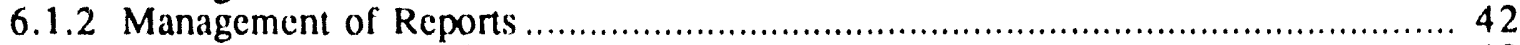

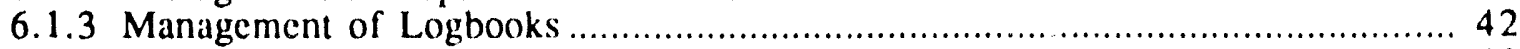

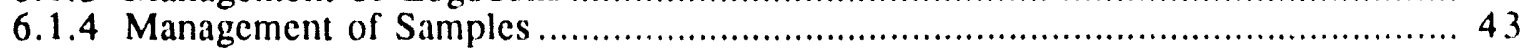

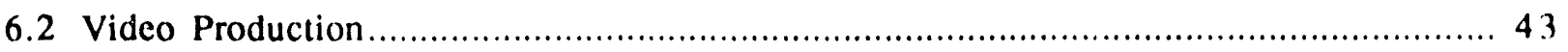

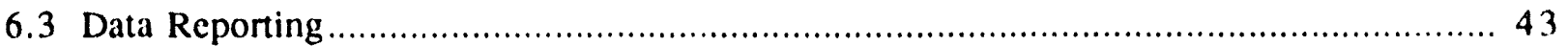

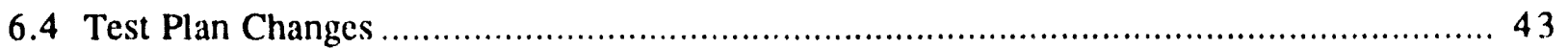

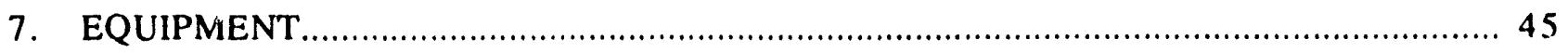

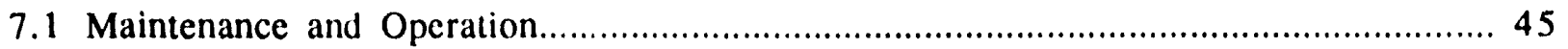

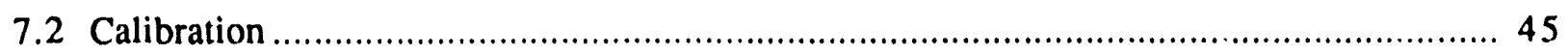

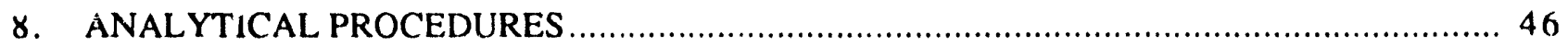

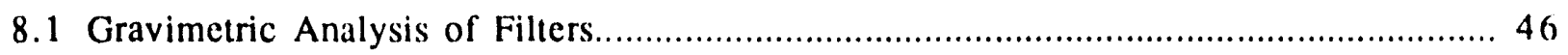

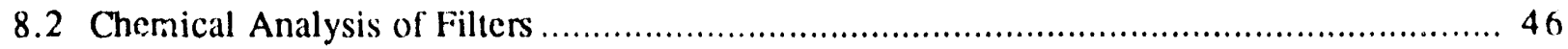

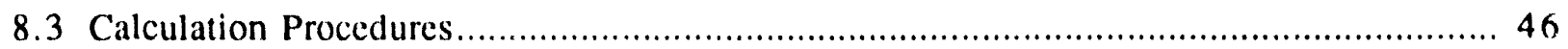

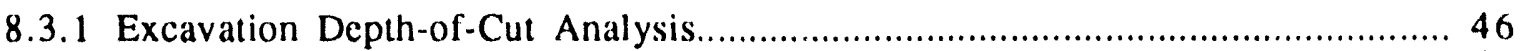

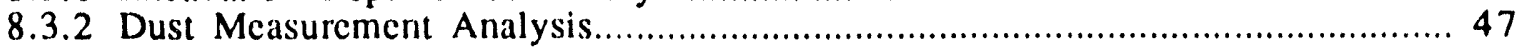

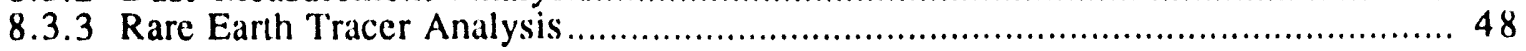

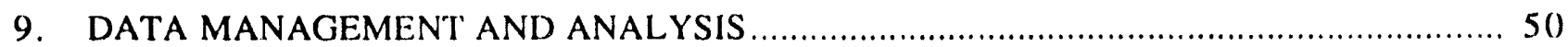

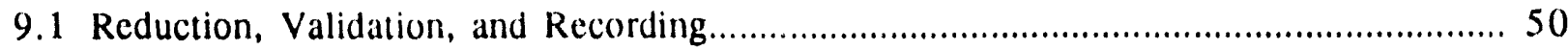

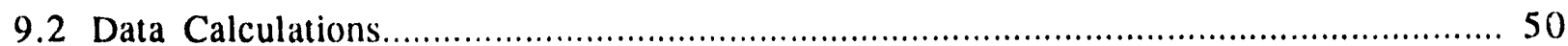


10. QUALITY ASSURANCE

10.1 Depth-of-Cut Measurements ............................................ 51

10.2 Dust and Contamination Measurements.............................................. 51

10.3 Ficld Monitoring and Maintenance ....................................... 5 I

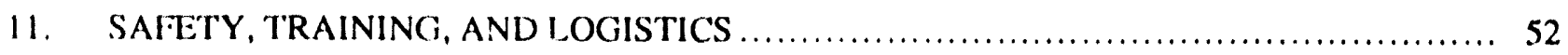

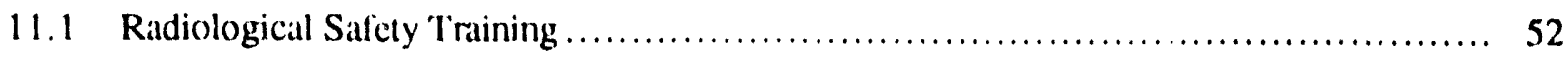

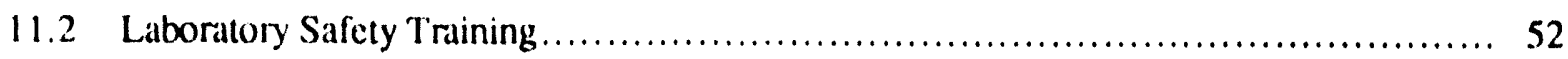

11.3 Waste Management Practices and Training................................... 52

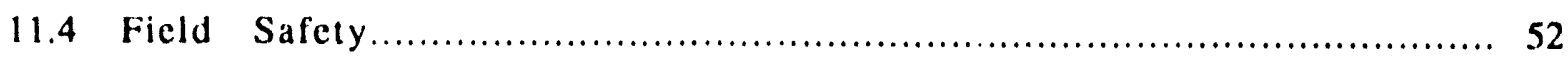

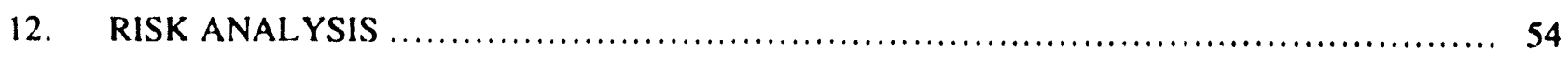

12.1 Lockout and Tagout ......................................................... 54

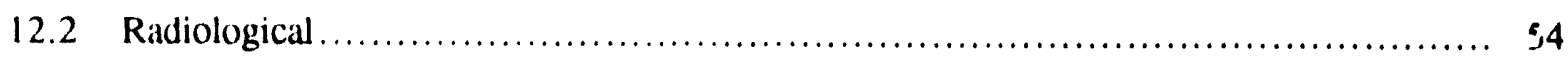

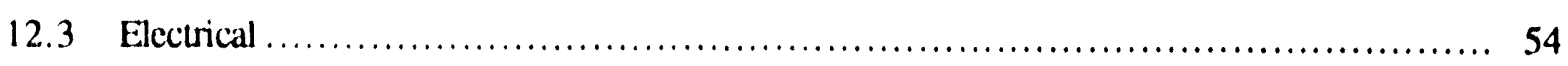

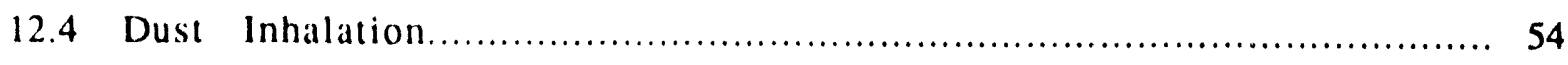

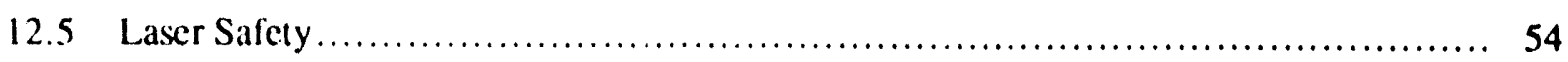

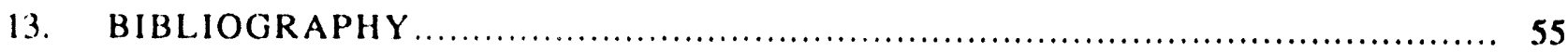

Appendix A-Detailed Test Procedure......................................................... A-1

FIGURES

1. The Cold Test Pit at the INEL is a nonradioactive, nonhazardous waste pit designed to simulate a TRU subsurface disposal pit or trench

2. Depth measurement data collected during the Phase I, II, and III tests will be recorded in a laboratory notebook.

3. The $10 \times 4()-f t$ zone that will be used to obtain soil cut measurements in the Phase I test must lic within the spiked soil zone

4. The rare earth tracer, erbium, will be placed in the overburden soil at levels significantly above background to provide a method of determining contamination spread.

5. Overburden removal demonstration organization chart..................................... 13

6. A general contour of the overburden on the Cold Test Pit will be obtained before beginning any soil removal operations

7. The Phase I demonstration will be conducted after a flat plane datum has been established. 
8. The side view of the excavation shows the relative position of the excalvator and air sampling equipment as well as the approximate location of the

47-mm samplers planted to be localted on the excavator

9. Depth-of-cut measurements will to: made utilizing the laser level transmitter

10. To de'ermine the precision and accuracy of the cuts, 10 measurements shall be taken on the centerline of the 3 ft excavator bucket approximately $30 \mathrm{ft}$ apart.

11. The Phase Il demonstration will be conducted after determination of the optimum cutting depth from Phase I has been made

12. An obstacle will be delineated in the overburden removal area to demonstrate the equipment and processes capability to maneuver around....

13. The production phase of the demonstration will provide data allowing determination of the rate of soil removal using the equipment and processes from the first two phases.

14. To ensure process control is being maintained during the production phase of the demonstration, a series of depth-of-cut measurements will be made

15. The Cold Test Pit is located south of the RWMC at the INEL

16. The excavator bucket is specifically designed to remove overburden soil

17. The excavator bucket uses controlled air flow to reduce dust generation and control the spread of contamination.

18. The excavator bucket has been designed to minimize soil disturbance

19. Cross sectional view of the HI-VOL air sampler

20. Forty-seven millimeter particulate air filters will be used to determine contamination spread and dust generation during the demonstration

21. Diagram of MSA cyclone sampler

22. The shaded zone in the above wind rose indicates the go-zone for performing contamination analysis dust collection

\section{TABLES}

1. Supporting personnel for the overburden removal demonstration.

2. Air sampling equipment, laturatory equipment and consumable (filters) are required to determine the contamination spread and dust generation of the overburden removal demonstration.

3. With the exception of the custom excavator bucket, standard construction equipment will be used in performing the demonstration. 


\section{ACRONYMS}

BWID Buried Waste Integration Demonstration

CFA Central Facilities Area

DOE U.S. Department of Encrgy

DQO Data Quality Objective

ECL Environmental Chemistry Laboratory

FY Fiscal year

HI-VOL High-volume air sampler

L.O-VOL Low-volume air sampler

ICP.MS Inductively Coupled Plasma-Mass Spectrometry

INEL Idaho National Engineering Laboratory

NOAA National Oceanic and Atmospheric Administration

OTD Office of Technology Development

PMP Project Management Plan

RWMC Radioactive Waste Management Complex

SDA Subsurface Disposal Area

SOP Standard Operating Procedure

TRU Transuranic

USID Uranium in Soils Integrated Demonstration 


\section{Test Plan for the Overburden Removal Demonstration}

\section{INTRODUCTION}

The purpose of this test plan is to outline the methods that will be used to evaluate soil overburden removal techniques. These techniques will be demonstrated at the Cold Test Pit during fiscal year (FY) 1993. The purpxese of these demonstrations is to evaluate the current technology in equipment and techniques for the removal of overburden soils at the Radioactive Waste Management Complex (RWMC) Subsurface Disposal Area (SDA) at the Idaho National Engineering Laboratory (INEL).

This test plan outlines the background information for the demonstration, discusses the organizational structure, outlines the objectives of the tests to be conducted, describes the methods and apparatus used to conduct the tests, and details the quality and safety requirements for these tests.

Although many methods for overburden soil removal exist, the funding available through the BWID Program is not adequate to demonstrate all of them; therefore, only the technique described in this test plan will be demonstlated this year. 


\section{PROJECT DESCRIPTION}

\subsection{Background Information}

During the period from 1950 to 1972 , over 2.3 million cubic feet of transuranic (TRU) wastes was disposed at the SDA in shallow land-filled pits and trenches. These wastes consist of drums, boxes, and large objects contaminated with TRU and organic materials. The primary hazards associated with these wastes are plutonium and americium compounds and organic solvents from We - rons production activities at the Rocky Flats Plant. These wastes were placed in pits and trenches and (: vered with an average of 3 to $5 \mathrm{ft}$ of soil as a cap to seal the pit or trench. In 1989, the RWMC becanie an Environmental Protection Agency (EPA) Superfund site. Current U.S. Department of Energy (DOE) plans to remediate the site include removal of the wastes fron these pits and trenches for further processing. To remove these wastes, the soil overburden must be removed. It is probable that during storage, many of the waste containers may have lost their integrity and the TRU materials have leached into the surrounding soil. Because of the possibility of contamination spread, removal of overburden soils must be accomplished in a manner that will minimize the generation and spread of contaminated soils. To meet this objective, the Office of Technology Development's (O'TD's) Buried Waste Integrated Demonstration (BWID) and Uranium in Soils Integrated Demonstration (USID) Programs will test soil overburden removal equipment and techniques during FY-93.

In 1988 EG\&G Idaho, Inc. constructed the Cold Test Pit. The Cold Test Pit provides an area to demonstrate retrieval technologies in a noncontaminated environment. The Cold Test Pit was constructed using simulated waste forms and storage configurations that mimic those found in the SDA (see Figire 1). The tests outlined in this document will be performed at the Cold Test Pit.

\subsection{Objectives}

The overall objective of this demonstration is to explore the effe tiveness of equipment that may ultimately be used to remove the overburden soil from TRU waste pits and trenches (i.e., to examine the feasibility). The data will eventually be used by Environmental Restoration during the feasibility study for parts of the RWMC and possibly by additional efforts in other locations. Data will also be used by Environmental Restoration to project additional technology needs for BWID out year planning. The overburden soil is expected to be clean; however, local hot spots may be present in the actual buried waste pits because of past burial practices and metcorological conditions. Therefore, the overburden must be removed in precise, controllable increments. Crucial technical aspects of the overburden removal include minimizing dust generation and the potential associated spread of airborne contaminants. It is anticipated that removal procedures will require both presampling of the excavation region and some screcning for hot spots during operations to preclude categorization of contaminated soil as clean soil.

The primary objectives for the test described in this plan are

- Demonstrate that increments of soil can be removed in predetermined and controlled thicknesses and determine the precision and accuracy of the removal equipment and processes. The demonstration includes using a standard modern hydraulic excavator with a specially adapted bucket to skim 3, 4, or 6 in. thick layers in $3 \mathrm{fi}$ wide strips from the Cold Test Pit. Bucket adaptations include depth control planes set for the proper depth-of-cut.

- Demonstrate the ability of the equipment and processes to control the generation of fugitive dust during removal of the soil and determine if dust was generated at the point of excavation at levels above background.

- Demonstrate the ability of the soil removal equipment and techniques to control the spread of contamination. By quantifying contamination spread using the collection and measurement of samples, determine if crbium was detected at levels above background during overburden soil removal operations. 


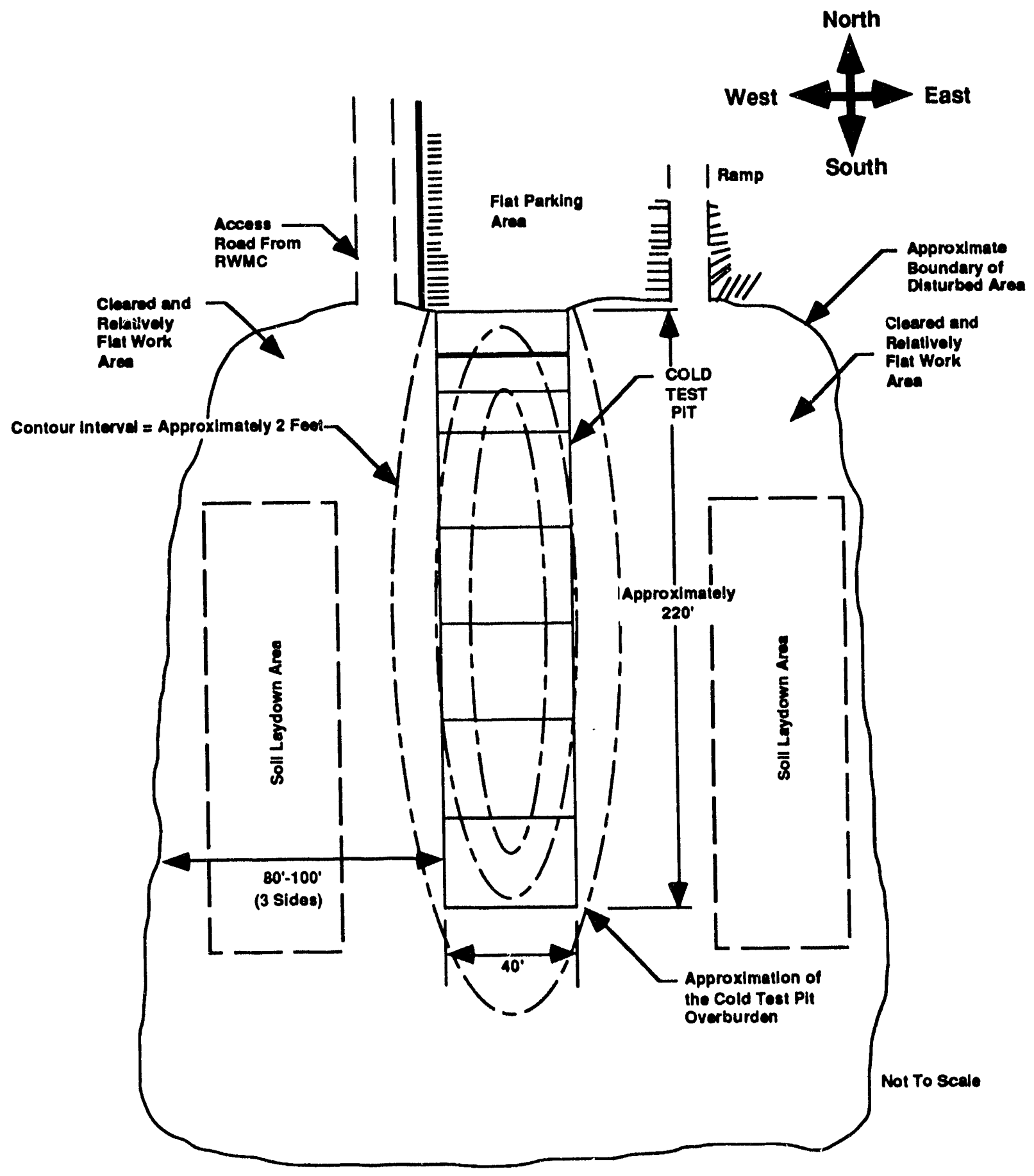

Figure 1. The Cold Test Pit at the INEL is a nonradioactive, nonhazardous waste pit designed to simulate a TRU subsurface disposal pit or trench. The sketch above shows a layout of the Cold Test Pit with the approximate contour of the overburden soil. The overburden is approximately 3 to $6 \mathrm{ft}$ thick and slopes gently in both the longitudinal and lateral directions to the crown. 
The secondary objectives for the test described in this plan are

- Demonstrate and measure the maneuverability of the removal equipment to work in or around the Cold Test Pit and excavate around simulated or real obstacles within the overburden removal area.

- Demonstrate that overburden soil can be removed at rates that would be representative of a production retrieval operation using the equipment, processes, and procedures described in this test plan.

This demonstration can be deemed a success if sufficient data and operations experience are gained to assess the capability of this technology to accomplish controlled removal of soil from a hot pit or contaminated area and if Environmental Restoration is provided with data to perform the feasibility studies. This determination will be made based on the following:

- Data adequate to determine the precision and accuracy of the removal of overburden soil in controlled increments at $3,4,6$, and 12 in.

- Collection of sufficient quantitative data to make a determination on the generation of dust during overburden soil removal at $3,4,6$, and 12 in.

- Collection of sufficient quantitative data to make a determination on the spread of contamination resulting from the application of the equipment and processes

- Collection of sufficient data to document the maneuverability envelope of the excavator and the excavator end-effector used in the demonstration

- Data adequate to document soil removal rates at 3,4, and 6 in.

These objectives shall be accomplished by using the methods described in this test plan.

\subsection{Data Quality Objectives}

Data will be obtained with the best available instrumentation within the stated budget of the project. All instrumentation will operate within the stated calibration range, with total uncertainty as stated in Sections 2.3.1 through 2.3.4.

The data quality objectives (DQO) include a review by the Sonsub, Inc., project manager and/or project engineer and EG\&G Idaho site representative to verify that data are within the performance specification as detailed in this test plan.

Details of the analytical procedures, including gravimetric analysis of the filters, chemical analysis of the filters, and calculation procedures are detailed in Section 8 "Analytical Procedures," of this test plan. Section 9, "Data Management and Analysis," describes reduction, validation, and recording of the data.

The following discussion of the detailed DQO includes a restatement of the test objective, the DQO for that test objective, and a statement of the uncertainty for the measurements to be taken to meet the DQO with a short discussion of how each uncertainty specification was derived. In some cases, a description of how the data and final analysis will be presented is given. Some of the data to be collected (i.e., soil moisture, humidity, etc.) will not be used directly in the analysis but are being collected out of convenience and in anticipation of its future value.

\subsubsection{Excavation Depth-of-Cut DQO}

Test Objective: Demonstrate that increments of soil can be removed in predetermined and controlled thicknesses and determine the precision and accuracy of the removal equipment and processes. The demonstration includes using a standard modem hydraulic excavator with a specially adapted bucket 
to skim 3, 4, or 6 in. thick layers in $3 \mathrm{ft}$ wide strips from the Cold Test Pit. Bucket adaptations include depth control planes set for the proper depth-of-cut.

Data Quality Objective: Determine with a 95\% confidence level that for any target increment depth specified, the increment of soil removed (depth-of-cut) is no deeper than 1 in. below that target depth. Figure 2 shows an example of the data form that will be used to collect the data to make this determination.

Uncertainty: The following total uncertainty specifications apply for the measurements:

- Depth of each cut: 1/4 in.

The $1 / 4$ in. total uncertainty was derived from manufacturer's data on the laser system and elevation measurement instruments.

- Location of the depth measuring rod in relation to the predefined grid points for the Phase I and II tests: 12 in.

The 12 in. total uncertainty was derived using engineering judgment. A tape measure will be placed in-line with the siting points, and a technician will take instrument readings every $2 \mathrm{ft}$. The 12 in. provide sufficient accuracy to fulfill the objective of the test while accounting for slight misalignment of the tape and placement errors of the measurement instrument.

\subsubsection{Dust Measurement DQO}

Test Objective: Demonstrate the ability of the equipment and processes to control the generation of fugitive dust during removal of the soil and determine if dust was generated at the point of excavation at levels above background. Dust generated will be controlled and exhausted to a collection point downwind of the air samplers.

Data Quality Qbjective: Determine with a 95\% confidence level that dust generation at levels 10 times above background level was detected. Data will be reported on a table similar to the Sample 1 table provided on page 9 .

Uncerrainty: The following total uncertainty specifications apply for the measurements:

- Air flow measurements through the particulate samplers: $10 \%$ of calibrated value.

The $10 \%$ flow total uncertainty was derived from the accuracy of calibration of the instruments used in this test for particulate air sampling.

- Mass measurements of the air sampler filters: $0.0001 \mathrm{~g}$.

The $0.0001 \mathrm{~g}$ total uncertainty was derived from the accuracy of calibration of the instruments used in this test for weighing the particulate air sample filters.

- Soil moisture measurements: To be determined.

Soil moisture detection equipment was not fully defined or characterized when this test plan was written. Equipment and total uncertainty of the instruments used to determine soil moisture will be reported in the final report. 


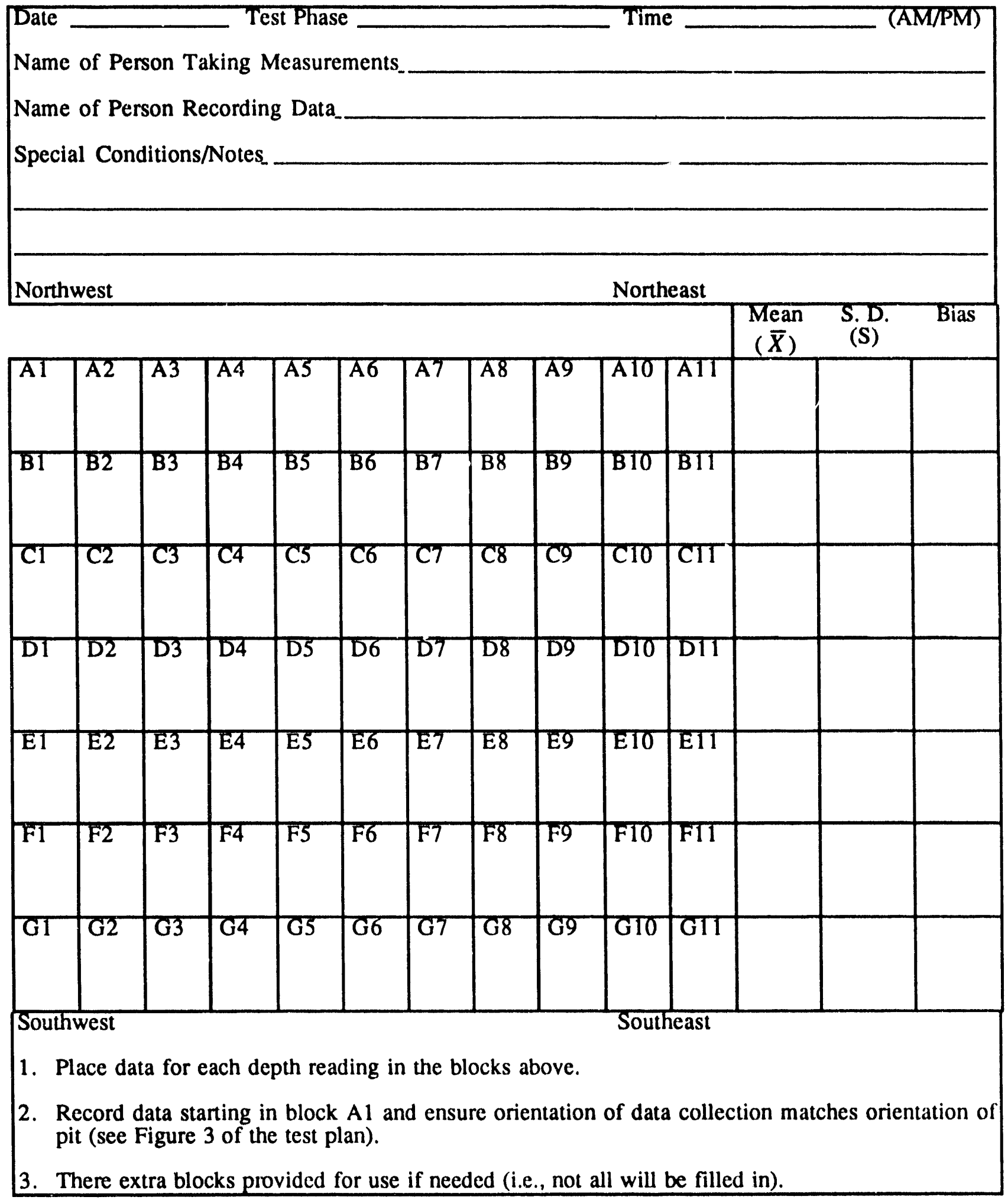

Figure 2. Depth measurement data collected during the Phase I, II, and III tests will be recorded in a laboratory notebook on a form similar to the one shown above. Figure 3 shows the relationship between the columns and rows of the data table and the measurement locations. 




Not To soalo

Figure 3. The $10 \times 40-\mathrm{ft}$ zone that will be used to obtain soil cut measurements in the Phase I test must lie within the spiked soil zone (see Figure 4). The measurements shall be taken on the centerline of the 3-ft excavator bucket approximately $9 \mathrm{ft}$ apart. Measurements shall be recorded as shown in Figure 2. Subsequent layers shall be removed in approximately the same location so that cut measurements can be taken in the same location. 


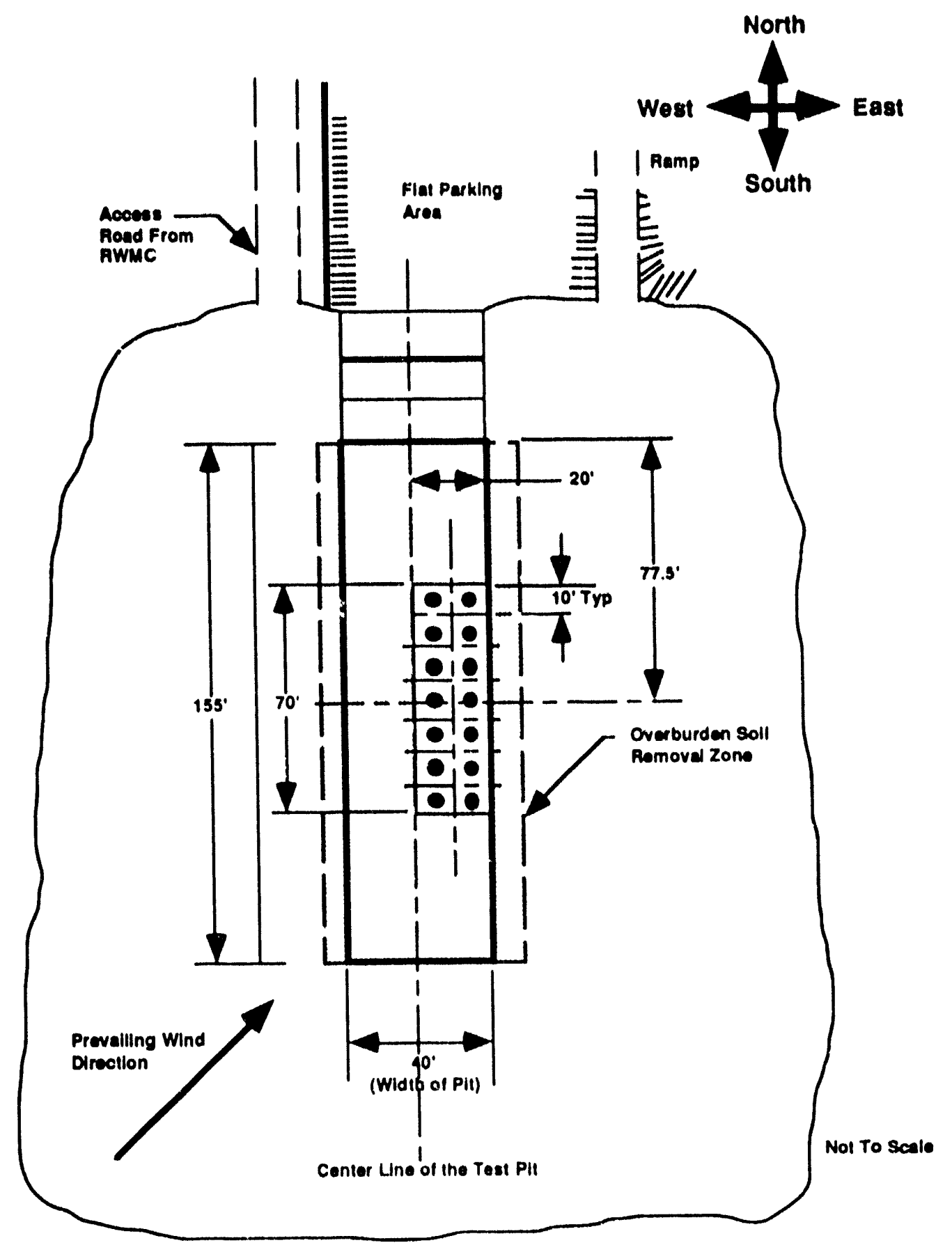

Figure 4. The rare earth tracer, erbium, will be placed in the overburden soil at levels significantly above background, to provide a method of determining contamination spread. The tracers will be placed on the east side of the test pit only in a $20 \times 70-\mathrm{ft}$ rectangle as shown. The west side will be used for the production demonstration, which will not involve air sampling. 
SAMPLE 1

\begin{tabular}{|c|c|c|c|c|}
\hline Test Phase & $\begin{array}{c}\text { Environmental } \\
\text { Conditions }\end{array}$ & $\begin{array}{l}\text { Soil Moisture } \\
\text { Measurement }\end{array}$ & $\begin{array}{c}\text { Dust Measurement } \\
\text { (mg/iter) }\end{array}$ & $\begin{array}{l}\text { Above or Below } \\
\text { Background Level }\end{array}$ \\
\hline Phase 1. 3" Layer & See NOAA Dala & & $\begin{array}{l}\text { Pretest Background } \\
\text { Mean Detected - } \\
\text { Test Background } \\
\text { Mean Detocled - } \\
\text { Test Sumples } \\
\text { Mean Detected. }\end{array}$ & \\
\hline Phase I . 4" Layer & See NOAA Dala & & $\begin{array}{l}\text { Prelest Beckground } \\
\text { Mean Delocled - } \\
\text { Test Background } \\
\text { Mean Detected - } \\
\text { Test Samples } \\
\text { Mean Delocted - }\end{array}$ & \\
\hline Phase 1. 6" Layer & See NOAA Dala & & $\begin{array}{l}\text { Preteat Background } \\
\text { Mean Detocled. } \\
\text { Test Background } \\
\text { Mean Delected - } \\
\text { Test Samples } \\
\text { Mean Detected. }\end{array}$ & \\
\hline Phase I - 12" Layer & See NOAA Data & & $\begin{array}{l}\text { Pretest Background } \\
\text { Mean Delected. } \\
\text { Test Background } \\
\text { Mean Detocted. } \\
\text { Test Samples } \\
\text { Mean Detocted. }\end{array}$ & \\
\hline Phase II & See NOAA Dala & & $\begin{array}{l}\text { Pretest Background } \\
\text { Mean Detocted. } \\
\text { Test Background } \\
\text { Mean Detocted - } \\
\text { Test Samples } \\
\text { Mean Detocted. }\end{array}$ & \\
\hline
\end{tabular}

\subsubsection{Rare Earth Tracer Analysls DQO}

Test Objective: Demonstrate the ability of the soil removal equipment and techniques to control the spread of contamination. By quantifying contamination spread using the collection and measurement of samples, determine if erbium was detected at levels above background during overburden soil removal operations.

Data Quality Objective: Determine with a $95 \%$ confidence level that the rare earth tracer, erbium, was detected at 10 times greater than background level. Data will be reported on a table similar to the Sample 2 table provided on page 10.

Uncertainty: The following total uncertainty specifications apply for the measurements:

- Air flow measurements through the particulate samplers: $10 \%$ of calibrated value.

The 10\% flow total uncertainty was derived from the accuracy of calibration of the instruments used in this test for particulate air sampling. 
SAMPLE 2

\begin{tabular}{|c|c|c|c|c|}
\hline Phase I Test & $\begin{array}{c}\text { Environmental } \\
\text { Conditions } \\
\end{array}$ & $\begin{array}{l}\text { Soil Moisture } \\
\text { Measurement }\end{array}$ & $\begin{array}{c}\text { Erbium Deteclod } \\
\text { (ppb) }\end{array}$ & $\begin{array}{l}\text { Above or Below } \\
\text { Background Level }\end{array}$ \\
\hline 3" Layer & See NOAA Data & & $\begin{array}{l}\text { Prelest Background } \\
\text { Mean Detocted . } \\
\text { Test Background } \\
\text { Mean Detected - } \\
\text { Test Samples } \\
\text { Mean Detected. }\end{array}$ & \\
\hline 4" Layer & Soe NOAA Data & & $\begin{array}{l}\text { Pretest Background } \\
\text { Mean Detected - } \\
\text { Test Background } \\
\text { Mean Detected - } \\
\text { Test Samples } \\
\text { Mean Detected - }\end{array}$ & \\
\hline 6" Layer & See NOAA Data & & $\begin{array}{l}\text { Pretest Background } \\
\text { Mean Detected - } \\
\text { Test Backgrnund } \\
\text { Mean Detected. } \\
\text { Test Samples } \\
\text { Mean Detected - }\end{array}$ & \\
\hline 12" Layer & Sce NOAA Data & & $\begin{array}{l}\text { Pretest Background } \\
\text { Mean Detected - } \\
\text { Test Background } \\
\text { Mean Detected - } \\
\text { Test Samples } \\
\text { Mean Detected - }\end{array}$ & \\
\hline
\end{tabular}

- Mass measurements of the air sampler filters: $0.0001 \mathrm{~g}$.

The $0.0001 \mathrm{~g}$ total uncertainty was derived from the accuracy of calibration of the instruments used in this test for weighing the particulate air sample filters.

- Analytical total uncertainty will be determined by the laboratory and analytical methods used and reported with the data.

Standards and duplicates will be used by the analytical laboratory to determine the total uncertainty of processes, procedures, and instrumentation utilized in analyzing the test results.

- Soil moisture measurements: To be determined

Soil moisture detection equipment was not fully defined or characterized when this test plan was written. Equipment and total uncertainty of the instruments used to determine soil moisture will be reported in the final report.

\subsubsection{Secondary DQOS}

Test Objective: Demonstrate and measure the maneuverability of the removal equipment to work in or around the Cold Test Pit and excavate around simulated or real obstacles within the overburden removal area.

Data Quality Objective: Document the maneuverability of the excavator and excavator end-effector used in the demonstration by direct measurements and photographic evidence. 
Uncertainty: The following total uncertainty specifications apply for the measurements:

- The track pattern required by the excavator to mancuver around the pit while completing a full length layer removal: $1 \mathrm{ft}$.

The 1-ft total uncertainty was derived using engineering judgment. This was selected because it is measurable with a noncalibrated instrument (tape measure) and provides sufficient accuracy to fulfill the objective of the test.

- The maneuverability of the bucket in terms of how well the 2:1 slope is held on the sides of the pit: 6 in.

The 6-in. total uncertainty was derived using engineering judgment. This was selected because it is easy to measure and provides sufficient accuracy to fulfill the objective of the test.

- The mearurement of how well the bucket can get to soil in the comers: 6 in.

The 6-in. total uncertainty was derived using engineering judgment. This was selected because it is easy to measure and provides sufficient accuracy to fulfill the objective of the test.

Test Objective: Demonstrate that overburden soil can be removed at rates that would be representative of a production retrieval operation using the equipment, processes, and procedures described in this test plan.

Dalla Quality Objective: Document the rate of overburden soil removal as performed during the demonstration by measuring the time of actual excavation and number of cubic yards of soil removed.

Uncertainty: The following total uncertainty specifications apply for the measurements:

- The volume of soil removed per complete layer: $1.0 \mathrm{yd}^{3}$.

The $1.0 \mathrm{yd}^{3}$ total uncertainty was derived using engineering judgment. The excavator bucket is capable of holding $1.0 \mathrm{yd}^{3}$. Allowing for judgment by ficld personnel of how full the bucket is, it was determined that this was an achievable goal.

- The time required during Phase III: 1 minute per cut.

The 1 minute total uncertainty was derived using enginecring judgment. This time accuracy was selected because it is easy to measure and provides sufficient accuracy to fulfill the objective of the test. 


\section{PROJECT ORGANIZATION}

\subsection{Buried Waste Integrated Demonstration Program}

The mission of the BWID Program is 10 demonstrate, test, and cvaluate technologies that are potentially faster, better, cheaper, and/or safer for restoring buried waste sites. BWID shall supply support facilities and utilities, and a coordinator for the overburden removal demonstration in July and August 1993. The main personnel supporting this task are provided in Table 1.

\subsection{Uranium in Soils Integrated Demonstration Program}

The mission of the USID Program is similar to that of the BWID Program. Its goal is lo demonstrate, test, and evaluate technologies that will assist in the remediation of soil. contaminated with uranium. USID is interested in the ability of the proposed system to precisely skim contaminated soils and is funding a portion of the demonstration at the INEL.

Figure 5 shows the organizational structure for the lests to be performed as described in this test plan. The funding organization for this test is the DOE OTD. EG\&Ci Idaho Environmental Restoration Technology Development Program Unit has direct fundirg throegh OTD to evaluate and demonstrate waste management and retrieval technologies for application to current DOE Environmental Restoration Programs. The key people in this project are

- BWID Integrated Demonstration Coordinator who is responsible for maintaining and coordinating overall technology demonstration activities in the area of techuology demonstration.

- BWID Project Manager who is responsible for overall performance of work 10 be conducted in the project. Maintains and tracks project funding and provides technical direction and expertise.

Table 1. Supporting personnel for the overburden removal demonstration.

\begin{tabular}{lll}
\multicolumn{1}{c}{ Name } & Affiliation & \multicolumn{1}{c}{ Responsibility } \\
\hline Guy Loomis & EG\&G Idaho & BWID Project Manager \\
Phil Rice & EG\&G Idaho & BWID Principle Investigator \\
Rudy Bonnenberg & EG\&G Idaho & BWID Cold Test Pit Support \\
Larry Watson & EG\&G Idaho & BWID RWMC Interface \\
Kevin Kostelnik & EG\&G Idaho & BWID Integrated Demonstration Condinator \\
Ken Merrill & EG\&G Idaho & BWID \\
Greg Anderson & EG\&G Idaho & Procurement Specialist \\
Lewis Rounds & EG\&G Idaho & Quality Assurance Engineer \\
John Morrison & EG\&G Idaho & BWII) Suppon \\
Richard Caummisar & EG\&G Idaho & RWMC Sifely Engineering \\
Jim O'Brien & EG\&G Idaho & RWMC Safety Engineering \\
Bob Heard & EG\&G Idaho & BWID Demonstration Coordination Manager \\
David Thompson & EG\&G Idaho & Project Scientist \\
Anita Freeman & EG\&G Idaho & Techincial Support \\
Chuck Yemington & Sonsub & Vendor Demonstration Program Manager \\
Bill Bath & Sonsub & Vendor Demonstration Chief Engineer \\
John Skaggs & Sonsub & Vendor Demonstration Project Engineer \\
Tom Bailey & Quality Steel & Vendor Demonstration Excivation Contractor \\
B. J. Reid & Sonsub & Vendor Demonstration Site Supervisor \\
Louis Cranek & Sonsub & Vendor Demonstration Site Supervisor \\
Mike Queen & Sonsub & Vendor Demonstration (uality Assurance Manager \\
\hline
\end{tabular}




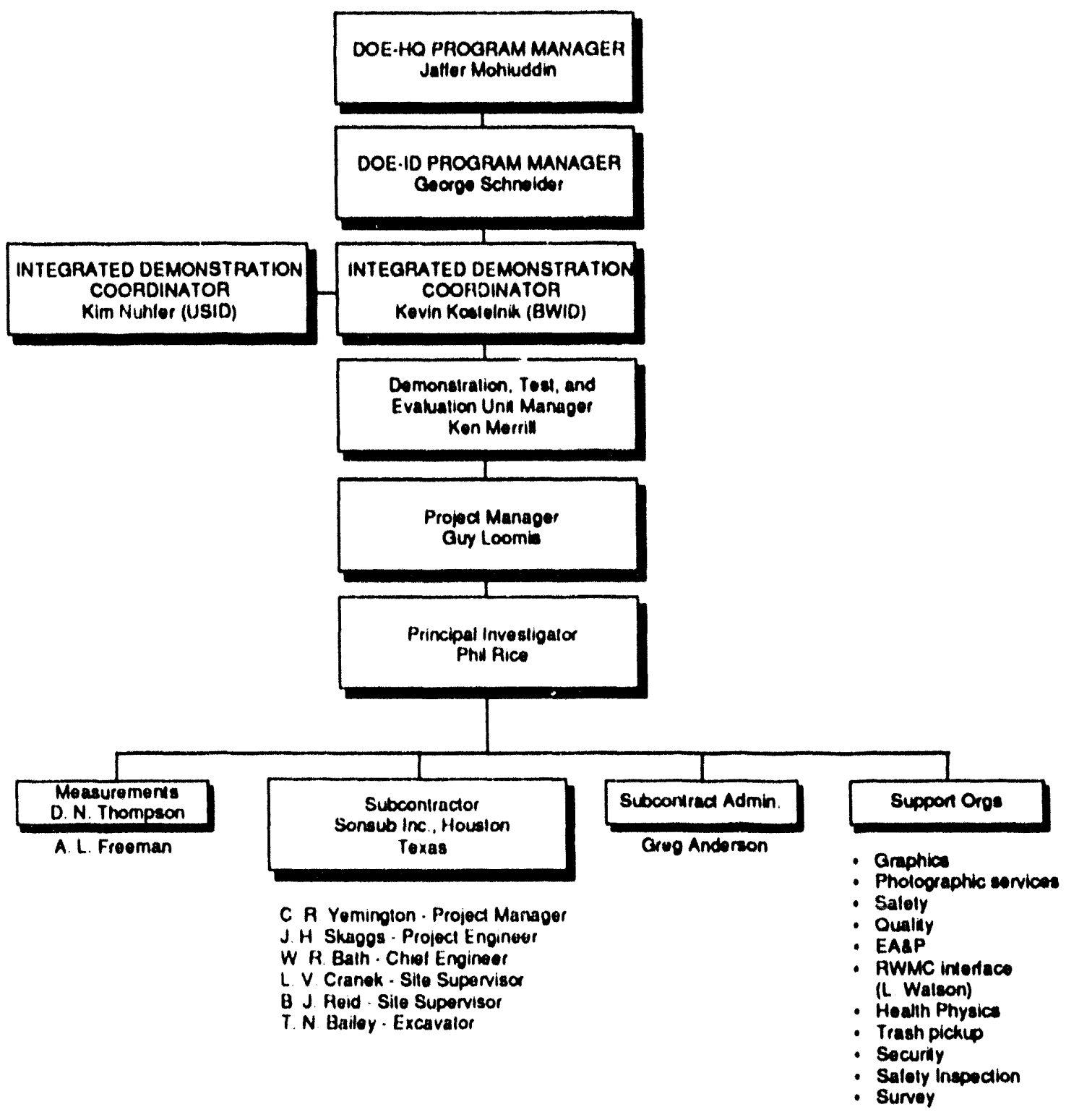

Figure 5. Overburden removal demonstration organization chart. 
- Work Package Manager (Principle Investigator) who is responsible for performance of all specific tasks in the project. Defines and writes statements of work, procures vendor services, and tracks and maintains project budgets and progress. Provides field technical suppor. Writes and publishes final report.

- Project Scientist who provides scientilic and technical support. Writes sampling and lest plans for performance of project tasks. Provides data analysis and interpretation. Assists work package manager in preparation of linal report.

- Field Team Leader who prepares and collects materials, data, and samples in the field. Procures sampling and analysis services and equipment. Provides technical direction and supporn to field sampling personnel.

- Field Sampling Personnel who collect data and samples in the ficld for analysis. 


\section{EXPERIMENTAL PLAN}

\subsection{Test Configurations}

The test will be conducted in three primary phases. The Phase l test will investigate the spread of contamination by measuring a specific rare earth tracer in particulate air samplers surrounding the test area. Data on dust gencration and the precision and accuracy of the increments of soil removed will also be collected. Phase II will be directed towarl determining the amount of dust created by the equipment and processes. Data on the precision and accuracy of the increments of soil removed will also be collected. Phase III will be used to determine the production capability of the equipment and processes used in the demonstration.

Outlined below is a general description of the experimental plan. Details on the execution of the test plan can be found in Section 5, "Test Procedures," and Appendix A.

\subsubsection{PIt Contour Measurement}

Before beginning excavation, the laser leveling system shall be used to plot a general elevation contour of the half of the Cold Test Pit that will be used for the Phase I and II tests. A grid of 30 points will be used for this plor. See Figure 6.

\subsubsection{Phase I Test-Contamination Spread}

The Phase I test includes the removal of four different controlled soil thicknesses totaling $2.5 \mathrm{in}$. over an area measuring at least $10 \times 40 \mathrm{ft}$. The $10 \times 40 \mathrm{ft}$ area shall be determined after a flat datum of at least this large is established. Layers of $3,4,6$, and 12 in. shall be removed in 3 ft wide strips. See Figures 3 and 7

- The actual depth for each cut shall be measured. The measurement will be attained manually at each point on a 30 point grid paltern utilizing a laser scanning system and a graduated survey mast with a laser receiver. These data shall be recorded on a specially prepared form for later consolidation. See Figures 2, 3, 8, and 9.

- Particulate air samples shall be collected at locations within and around the test area as shown in Figure 7. Air filters have been placed between the excavator and pit, downwind of the excavation. This positioning was selected so that data could be gathered on the performance of the excavator bucket with minimal disturbance caused by moving the excavator and dumping the soil on the laydown area. The samplers were placed close together and evenly spaced along the $4(1)$ fi test area to gather the maximum amount of data and minimize the effects of possible dust plumes that could escape detection. Filter samples shall be collected from 47-mm low volume (LO-VOL) and high volume (HI-VOL.) air samplers. In addition two LO-VOL. samplers shall be located on the excavator: one on or near the bucket and the other on top of the excavalor (see Figures 7 and 8). Filters shall be changed out between each cul giving dust generation and contamination spread data for each of the 3, 4, 6, and 12 in. intervals. Test runs and air samples may be repeated at the discretion of the EG\&G Idaho site representative to account for meteorological disturbances.

- Time studies shall be performed to determine the time rate of soil removal for each of the test runs and establish the bascline performance and procedures for the remaining phases of the kist.

\subsubsection{Phase II Test-Dust Generation}

The Phase II test includes the removal of soil in layers over an area covering approximately the castern one half of the Cold Test Pit. This phase will begin at the completion of the Phase I test. The thickness of the layers 10 be removed in this test will be determined from the results of the Phase I lest and will be either 3,4, or 6 in deep. The determination will be made based on which depth selling provided the hest precision and accuracy combined with the judgment of the contractor 


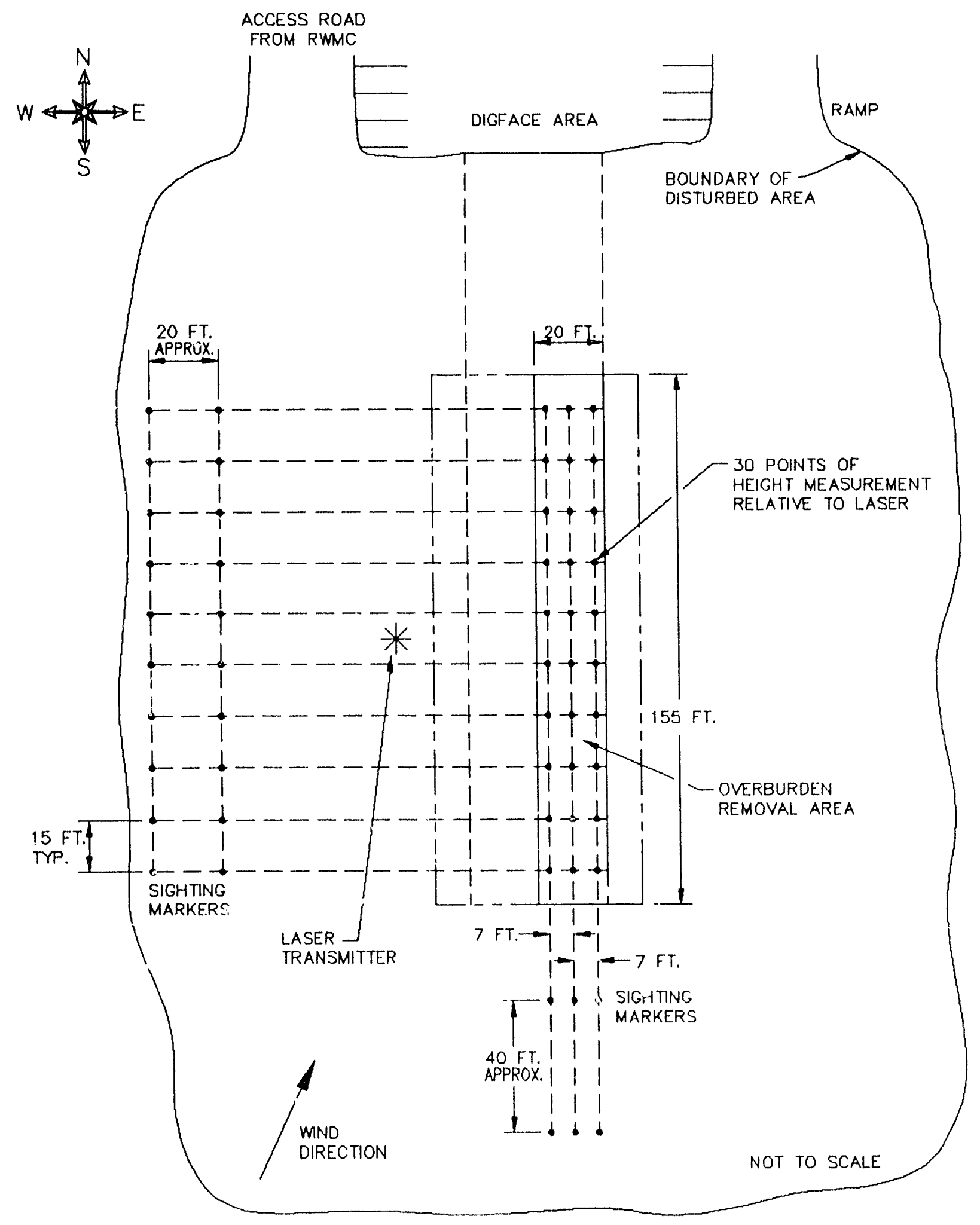

Figure 6. A general contour of the overburden on the Cold Test Pit will be obtained before beginning any soil removal operations. 


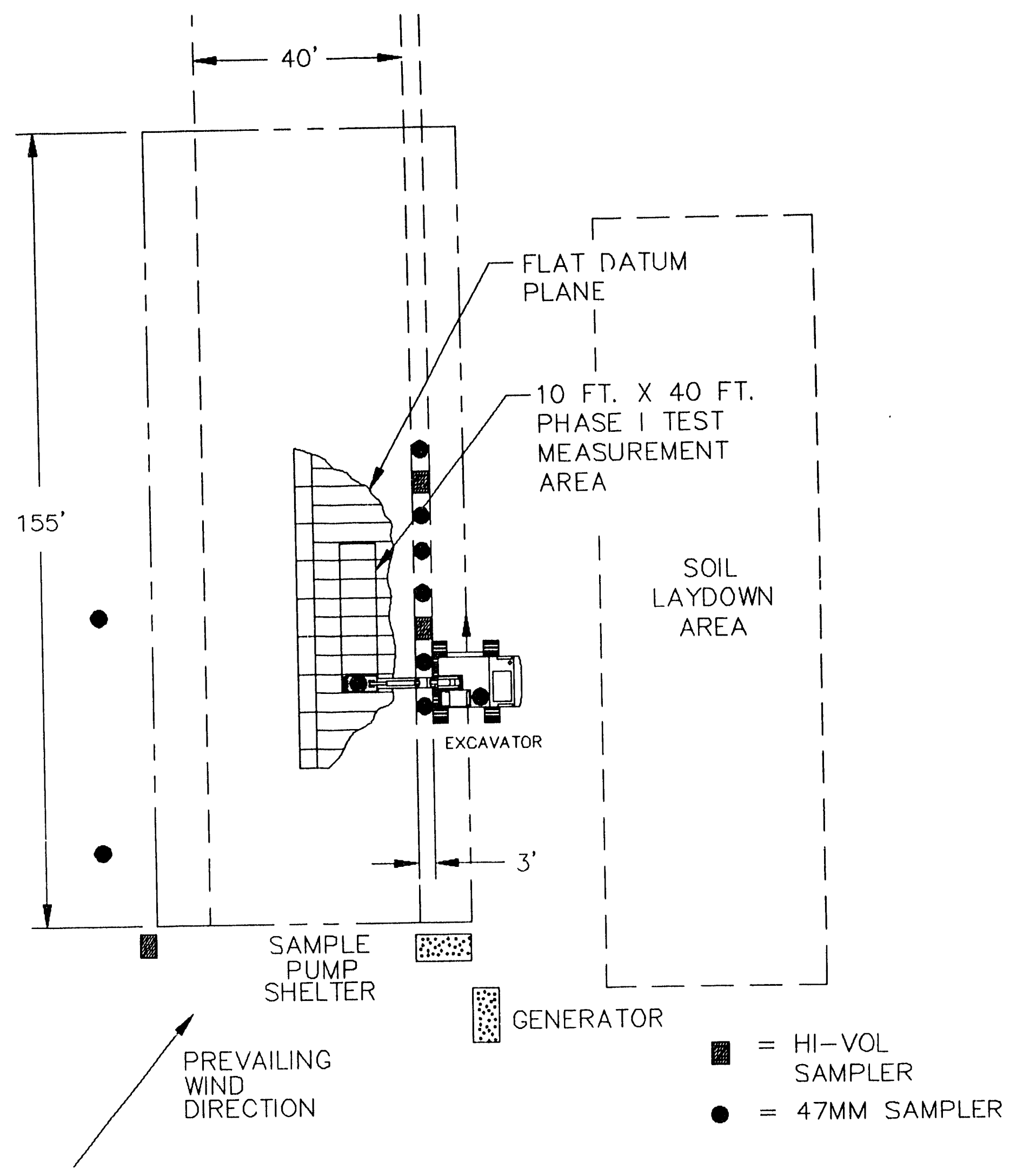

Figure 7. The Phase I demonstration will be conducted after a flat plane datum has been established. Air monitors will be grouped closely in the $10 \times 40-\mathrm{ft}$ zone to get contamination spread data for each of the $3,4,6$, and 12 -in. cuts. 


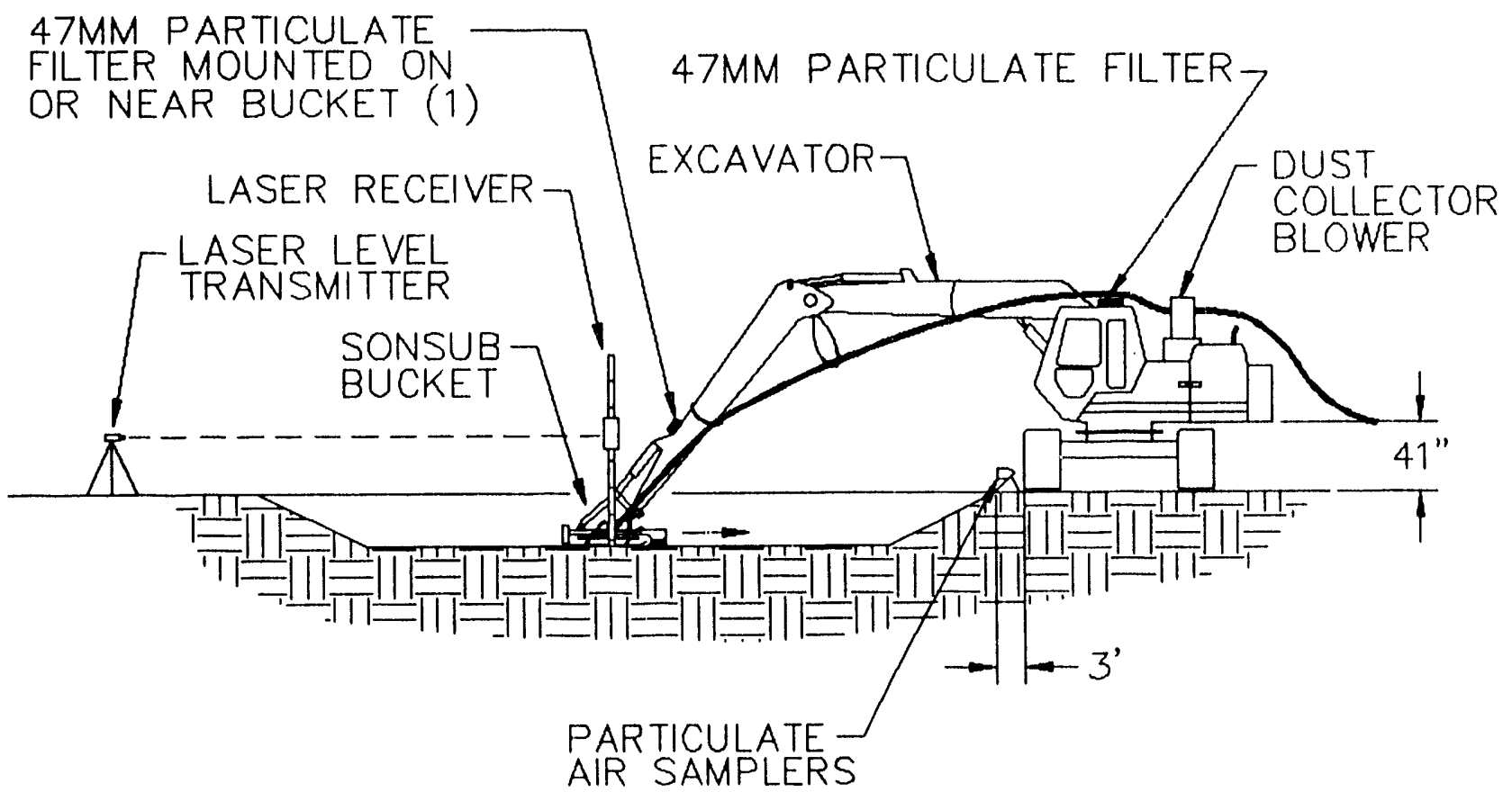

Flgure 8. The side view of the excavation shows the relative position of the excavator and air sampling equipment as well as the approximate location of the $47-\mathrm{mm}$ samplers planned to be located on the excavator.

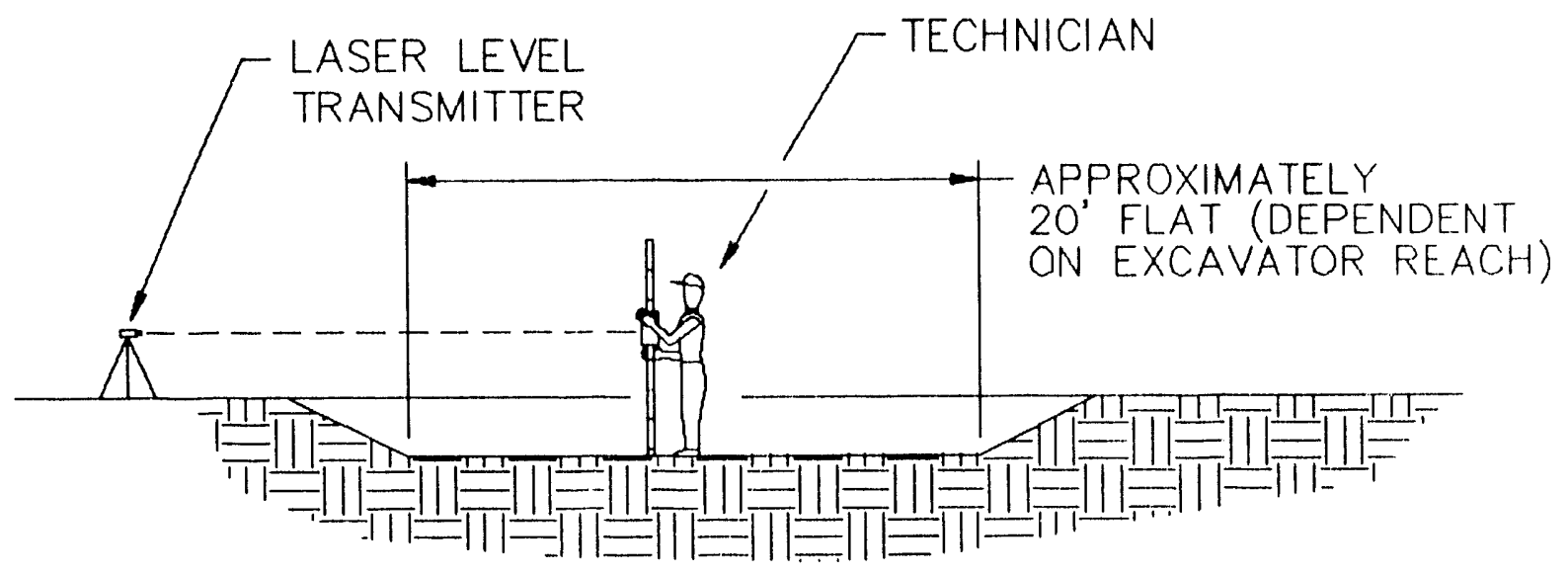

Flgure 9. Depth-of-cut measurements will be made utilizing the laser level transmitter. 
personnel and the EG\&G Idaho representative. The overburden removal shall continue at the discretion of the EG\&G Idaho site representative but at no time shall exceed $6 \mathrm{ft}$ in depth from the high point of the overburden crown. If nonhazardous, nonradioactive simulated waste is encountered during the excavation, the EG\&G Idaho site representative will cordon off the area where the object(s) are encountered and direct that excavation continue around this area.

- The actual depth for each cut shall be measured. The measurement will be attained manually at each point on a 50 point grid pattern utilizing a laser scanning system and a graduated survey mast with a laser receiver. These data shall be recorded on a specially prepared form for later consolidation. See Figures 3, 8, 9, and 10.

- Particulate air samples shall be collected at locations within and around the test area. Filter samples shall be collected from LO-VOL and HI-VOL air samplers. In addition, two LO-VOL samplers shall be located on the excavator: one on or near the bucket and the other on top of the excavator. Dust generation data shall be measured during this phase of the test. If the continuous wind speed exceeds $15 \mathrm{mph}$, then the tests will be halted and new filters placed in the particulate dust monitors. The test will be resumed with dust data taken at the higher wind velocity. Test runs and air samples may be repeated or additional data taken at the discretion of the EG\&G Idaho site representative to account for meteorological disturbances. Whenever filters are changed, data on the reasons for changing the filters shall be recorded in the logbook, along with the time of day and meteorological conditions at the time of the change. No contamination spread data will be taken during Phase II.

- During this phase, an obstacle shall be marked in the center area of the pit. The excavator shall be required to excavate around this obstacle leaving a 2 to 1 slope as required around its sides. See Figures 11 and 12. Measurements shall be taken to determine the capability of the equipment to maneuver around the obstacle. A tape measure and photography will be used to document maneuverability, and sketches will be made.

- Time studies shall be performed to determine the time rate of soil removal for each of the test runs and establish the baseline performance and procedures for comparison to the other phases of the test.

\subsubsection{Phase III-Production}

At the completion of the Phase II test or at the discretion of the EG\&G Idaho site representative, the excavator shall be moved to the western side of the Cold Test Pit. During this phase, layers of overburden soil shall be removed in $3 \mathrm{ft}$ wide strips at a depth to be determined in Phase II. No dust or contamination spread measurements will be taken during this phase of the test. Also, this test series will not be restricted on wind velocity and direction as the previous two phases, except for health and safety reasons. See Figure 13. The overburden removal shall continue at the discretion of the EG\&G Idaho site representative but at no time shall exceed $6 \mathrm{ft}$ in depth from the high point of the overburden crown. If nonhazardous, nonradioactive simulated waste is encountered during the excavation, the EG\&G Idaho site representative will cordon off the area where the object( $(s)$ are encountered and direct that excavation continue around this area.

- The actual depth for some increments of soil removed shall be measured to determine that depth control is being maintained under the Phase III test "Production." The measurement will be attained manually at each point on a 50 point grid pattern utilizing a laser scanning system and a graduated survey mast with a laser receiver. The measurements shall be nonintrusive, that is they should not interfere with the excavation. This data shall be recorded on a specially prepared form for later consolidation. See Figures 3, 8, 9, and 14.

- Time studies shall be performed to determine the time rate of soil removal (actual volume removed versus time required shall be recorded) for each of the test runs and establish the baseline performance for comparison to the other phases of the test. 


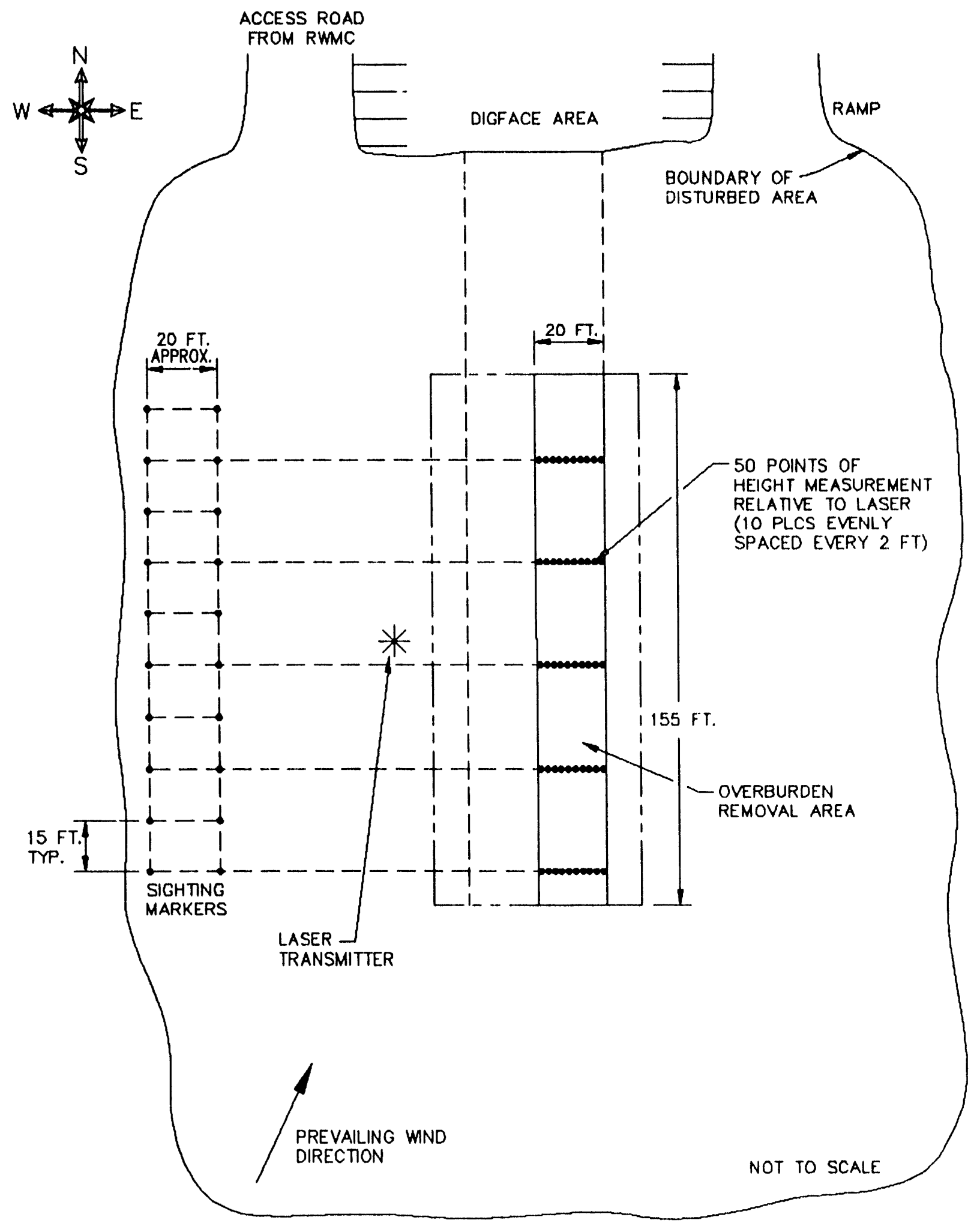

Figure 10. To determine the precision and accuracy of the cuts, 10 measurements shall be taken on the centerline of the 3 -ft excavator bucket approximately $30 \mathrm{ft}$ apart. Subsequent layers shall be removed in approximately the same location so that cut measurements can be taken in the same location. 


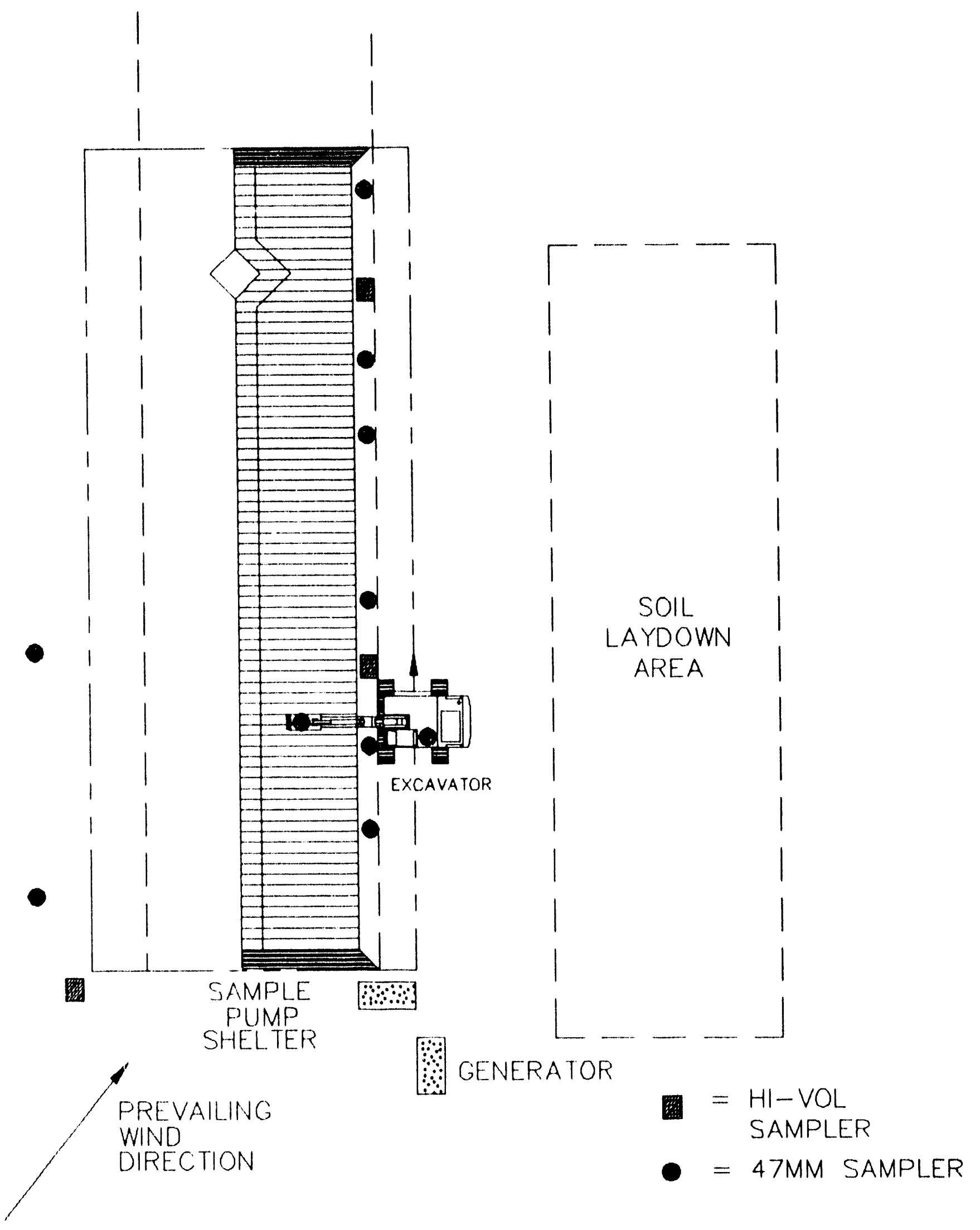

Figure 11. The Phase II demonstration will be conducted after determination of the optimum culting depth from Phase I has been made. Air monitors will be spread along the length of the pit to gather dust generation data. 


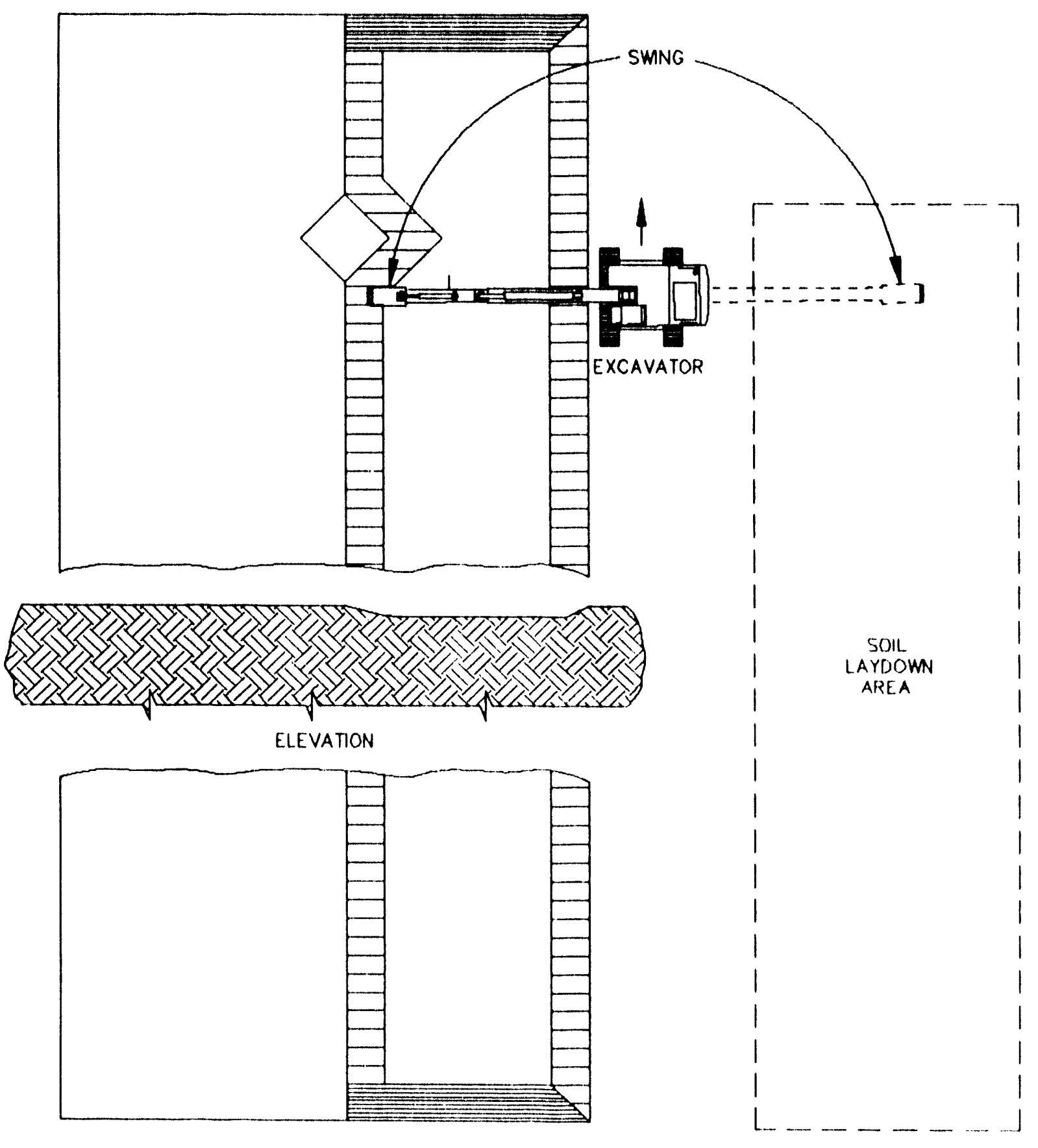

Figure 12. An obstacle will be delineated in the overburden removal area to demonstrate the ecjuipment and processes capability 10 minneuver around. 


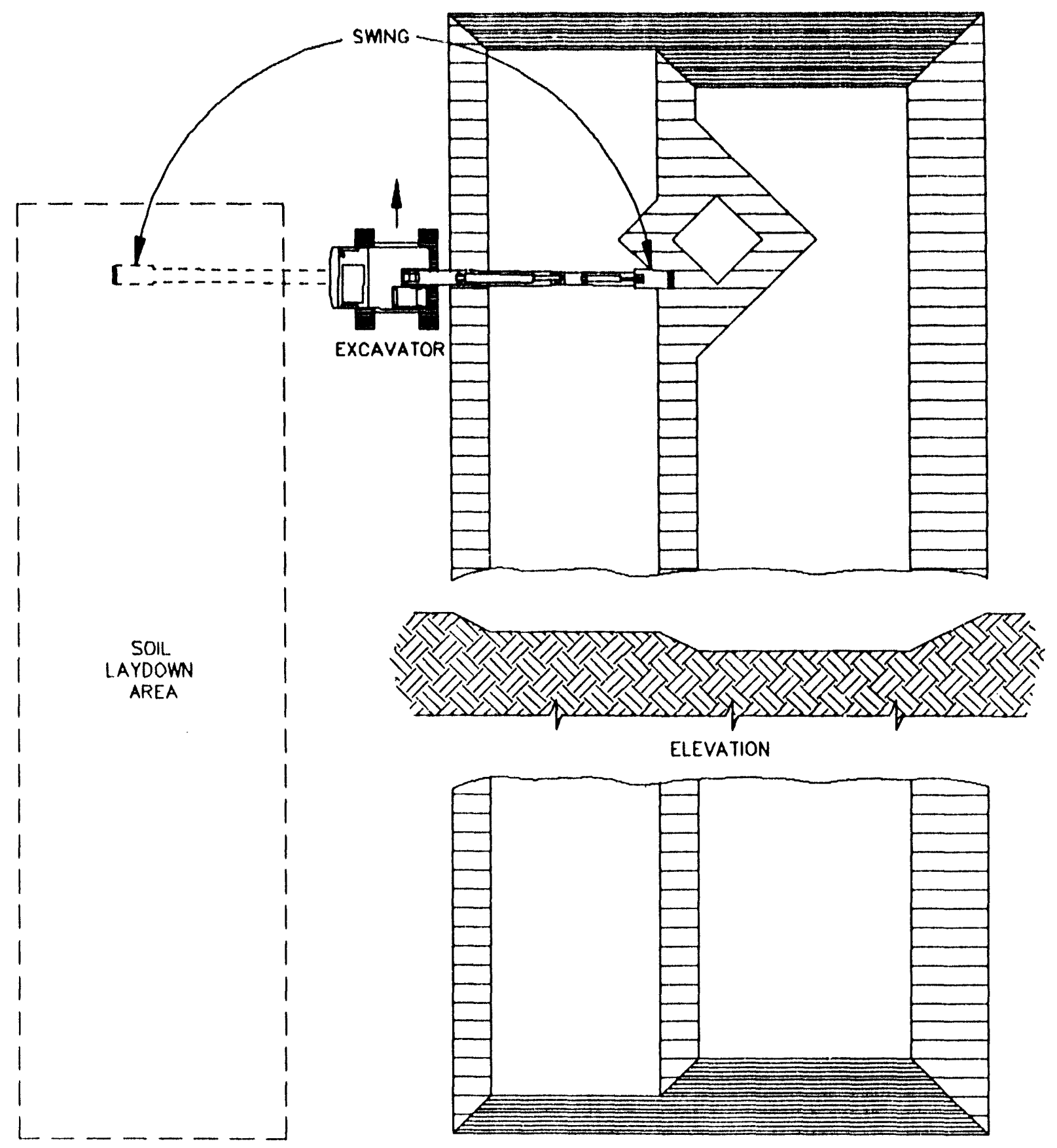

Figure 13. The production phase of the demonstration will provide data allowing determination of the rate of soil removal using the equipment and processes from the first two phases. Some depth-ofcut measurements will be made to ensure process control is being maintained. 


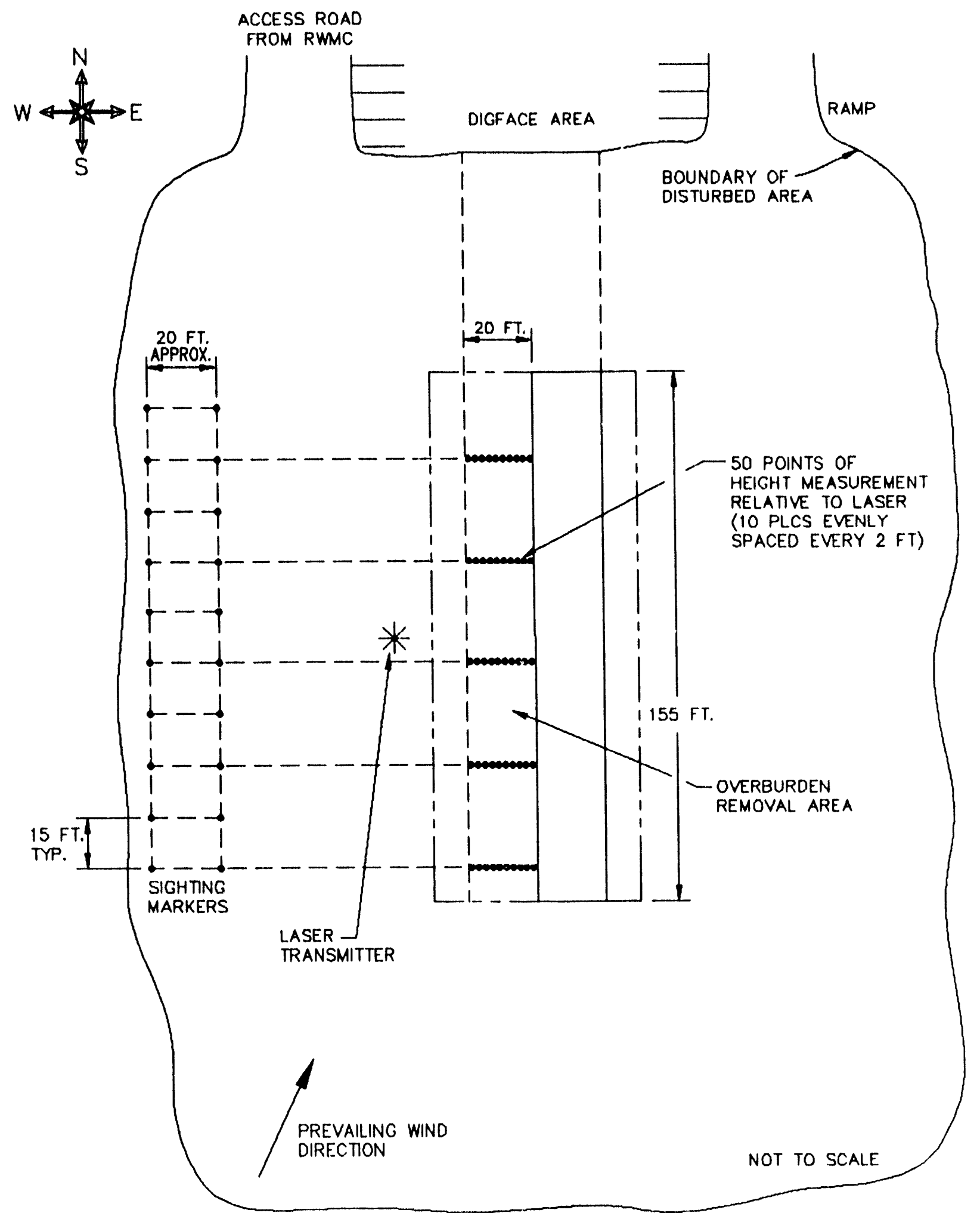

Flgure 14. To ensure process control is being maintained during the production phase of the demonstration, a series of depth-of-cut measurements will be made. 
- During this phase, an obstacle shall be marked in the center area of the pit. The excavator shall be required to excavate around this obstacle leaving a 2 to I slope as required around its sides. See Figures 11 and 12. Measurements shall be take to determine the capability of the equipment to maneuver around the obstacle.

NOTE-No dust generation data will be gathered during this phase of the test. Therefore, it is critical that the processes and procedures used in Phase III are as similar as possible to the Phase I and II tests so that comparisons can be made between the dust generation measured in the Phase I and II tests and production rates to be developed in the Phase III tests.

\subsubsection{Excavator Track Mapplng}

Once the flat datum is established, the approximate track pattern required by the excavator to mancuver around the pit while completing a full length layer removal will be recorded in the test logbooks. This information shall be recorded for each test phase and will be used to determine the area that would be required outside of the perimeter of a hot pit for safely maneuvering an excavator of this size class.

\subsubsection{Unusual Events}

Any unusual events shall be recorded in the test logbooks by still photography and/or video. An unusual event is any event not expected to occur during the tests. Examples of unusual events include but are not limited to equipment breakdowns, unique environmental conditions (such as rain), contacting waste while removing overburden, and operational problems with the design of the equipment, processes, and procedures.

\subsection{Apparatus}

The Cold Test Pit is located south of the RWMC at the INEL (see Figure 15). A diagram showing the layout and dimensions of the Cold Test Pit is shown in Figure 1. The Cold Test Pit is constructed using drums and boxes to simulate actual TRU waste form types and contents and divided into separate cells 10 mimic the different types of waste form placement. The Cold Test Pit has a soil cap or overburden placed over the top. All of these conditions are similar to those found within the SDA. Each of the waste forms has been laced with rare earth tracers (dysprosium, terbium, neodymium, and ytterbium) to simulate TRU contamination. The tracers are designed to provide a method to evaluate the ability of retrieval or waste handling technology or equipment to control the release of contamination from the waste forms while operations are taking place. Previous demonstrations at the Cold Test Pit included the collection of air particulate samples during activities and analyzing those samples for the specific rare earth tracer. The soil overburden currently has no tracer in place. The concept to be tested in this project is test specific equipment and techniques for removing soil overburden.

\subsubsection{Excavator}

A standard modem hydraulic excavator in the $43,00(0)$-lb class will be leased for the project. A special bucket will be mounted to the excavator that incorporates features to control the depth-of-cut and dust. The other equipment that are required for the demonstration, such as a small bulldozer and a generator, are readily available and can be leased. The excavator operates above the pit on uncut overburden where soil loading is least critical. The proposed excavator has rated ground pressure as low as 4.12 psi depending upon tread type. (Equipment used for the demonstration may be slightly higher depending upon local availability to support the demonstration schedule.)

\subsubsection{Excavator Bucket}

Figure 16 illustrates the excavator bucket. Adjustable depth control planes are mounted on each side of the bucket. Both planes can be set at 3, 4, or 6 in. above the bucket lip for the first cut. 


\section{Radioactive Waste Management Complex}

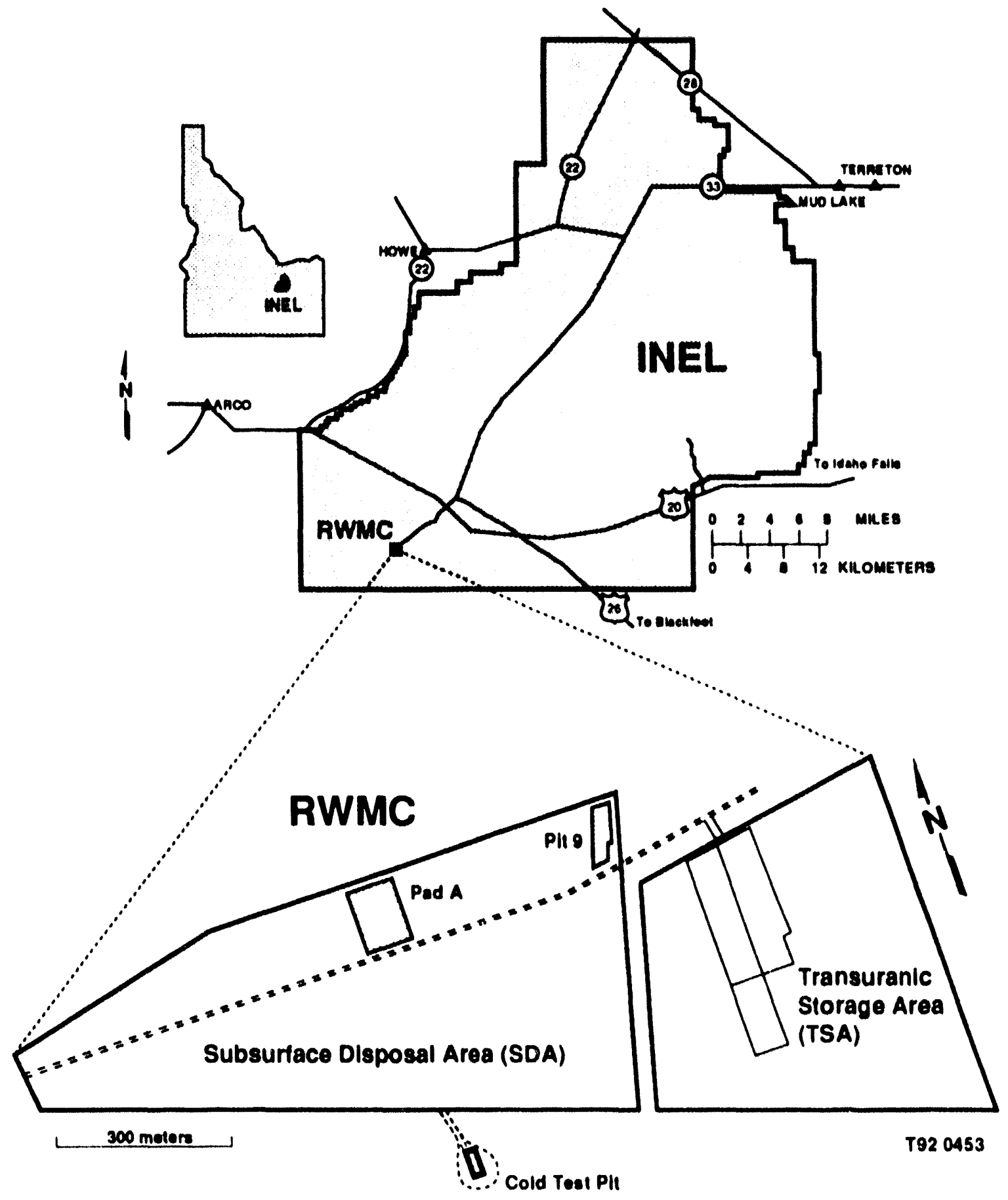

Figure 15. The Cold Test Pit is located south of the RWMC at the INEL. 
ADJUSTABLE DEPTH CONTROL PL.ANE 7
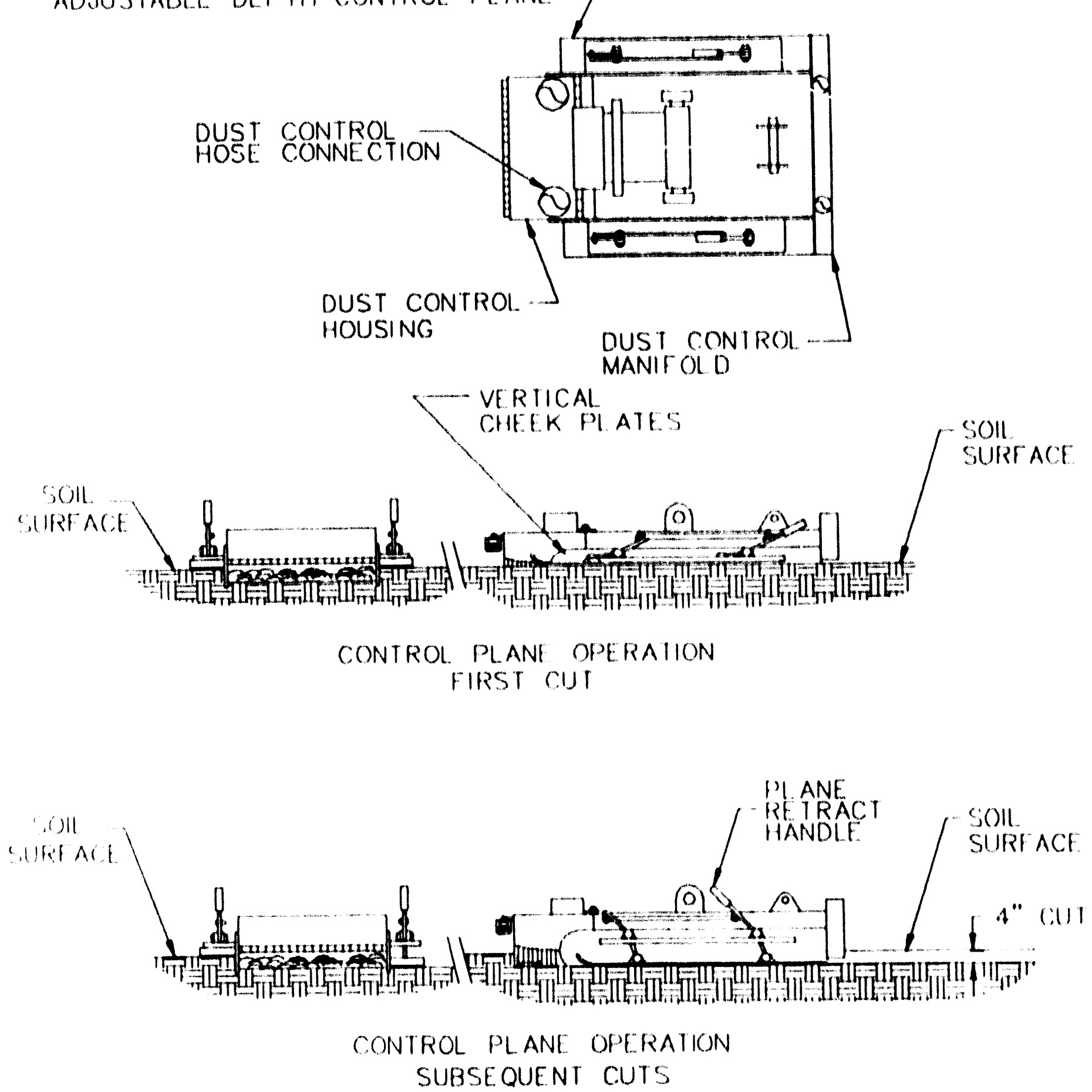

Flgure 16. The excavator bucket is specifically designed to remove overburden soil. It contains feitures to reduce the generation of dust and control the thickness of soil removed. 
For subseguent cuts, one plane is set level with the bucket lip. The lower plane rides on the surface cut immediately before the level plane. The higher depth control plane, on the other side of the bucket, rides on the surface, which will be removed immediately by the next sc(x)p.

The depth ecntrol planes rise in front like sled runners to ensure that the planes ride on the reference surface and do not dig in. The depth eontrol planes hold the bucket horizontal to ensure an effective horizontal slicing motion as it is drawn along. As a monitor for the depth being cut, a commercially available laser system provides a visible reference that tells the operator if the bucket is high, low, or on line for lie cut heing perforned. To avoid plowing soil into a trail along the edges of the bucket mouth, vertical check plates cut the overburden ahead of the bucket lip and ensure that all disturted soil moves into the bucket. The overburden outside the verticial check plates is packed down by the depth control planes to reduce dust at the trailing edge of the bucket.

\subsubsection{Dust Collection System}

Figures 17 and 18 illustrate the dust collection system. This method mects the dust control criteria using a dual approach that minimizes soil disturbance and incorporates active dust control. The total dust control system includes an excavator that does not run on poltentially contarninated soil, controlled air now on the bucket, and exhaust system to pull the dust away from the work 10 a collection or distribution point. As shown in Figure 17, negative air pressure is maintained inside the bucket and in an air manifold along the trailing edge to draw dust into the dust control system

As shown in Figure 18, an air control nap across the front of the bucket provides an air daun to help maintain negative pressure inside the bucket while allowing for surfaci irregularities. As the full bucket is lifted, this nap stays in contact with the soil, forces air to flow over the hucket lip, and scavenges dust generated as the bucket disengages the soil

The smooth undersurface of the bucket and depth control planes help to minimize dust generation along the trailing edges. In addition. the dir intake manifold allong the outside trailing edge of the bucket and depin control planes draws in any dust generated there. The bucket has a replaceable straight cutting lip rather than tecth. This minimizes soil disturbance ahead of the bucket and the amount of disturbed soil that is left behind as the bucket lifts up Spillage is further reduced by ending each stroke at the pit wall where llie bucket can be tilted to follow the wall up, llereby allowing disturbed soil to fall into the bucket as the buckel is disengaged from the ground.

Dust control during dumping is not within the scope of this demonstration. It is, however. recognized that dust from dumping must te kept away from the dust monitor intakes. Therefore, a large hose will transpon the conveyed dust downwind from the excavalion site and downwind from the excavator. For this demonstration, the dust will be simply dispersed at the end of the hose

The soil laydown area will be covered at night and during any periods of wind reversal $(0$ help prevent dust from the soil pile contaminating the test area.

\subsubsection{Laser Reference System}

The laser leveling system is an off- the -shelf, commercially available system used for grade control in the construction and agricultural industries. This system will be rented for use during this demonstration. The system includes a low level laser transmiller mounted on a tripod. The Iransmilter emits a thin 360 ) degrece rotating bean lo provide a constant grade reference at every point over the site. A receiver mounted on a mast connected to the excavalor bucket will visually indicate to the operator if it is high, low, or on grade. A second receiver mounted on a malnual surveyors mast will be used to take the intial comfour measurements and all depth of ecut measurements isee Figure ()).

These systems are available from several manufacturers. The actual system used for llie demonstration will be delerminted by avalability at the lime of rental. 

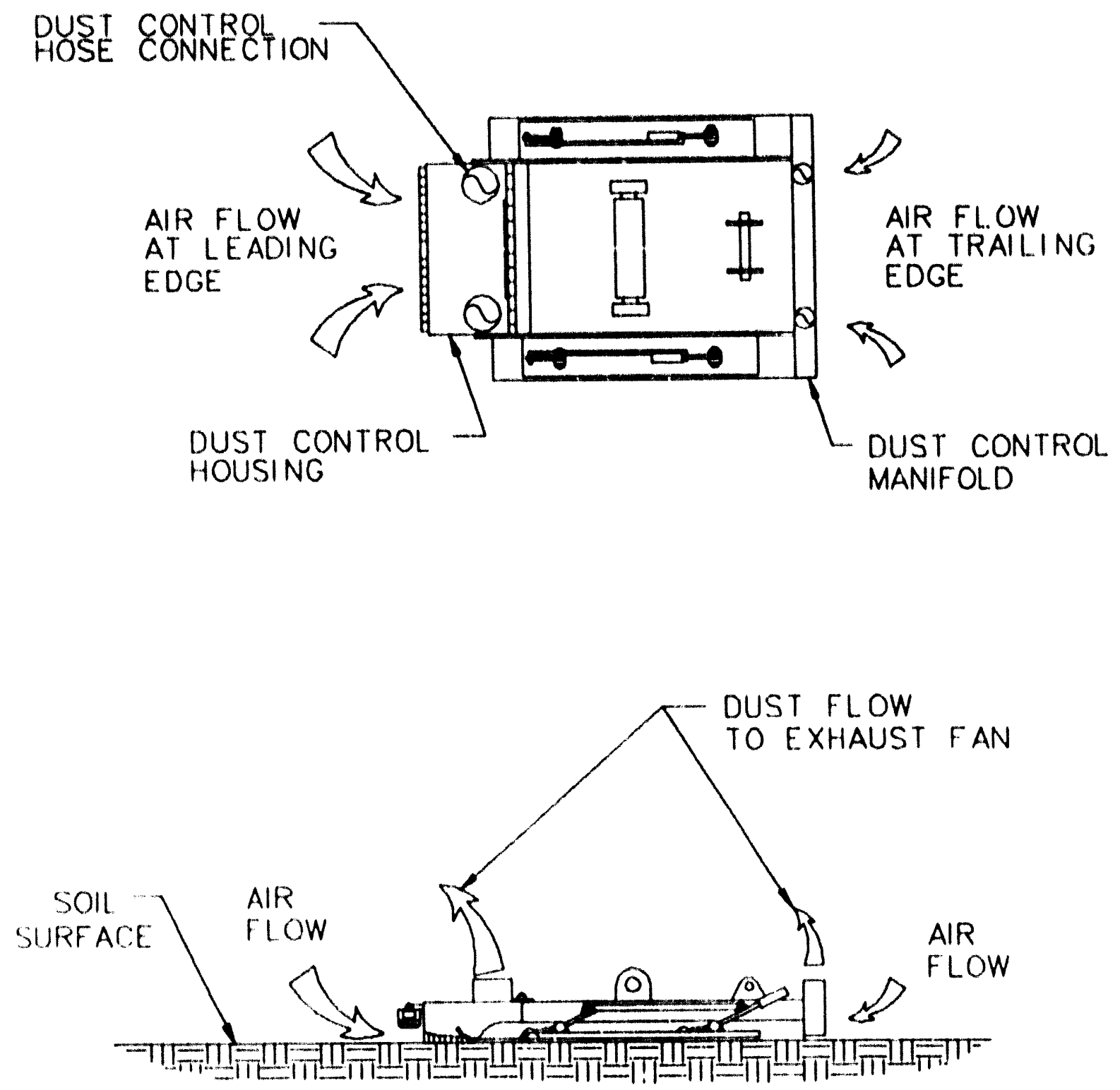

Figure 17. The excavator bucket uses controlled air now to reduce dust generation and control the spread of contamination. 


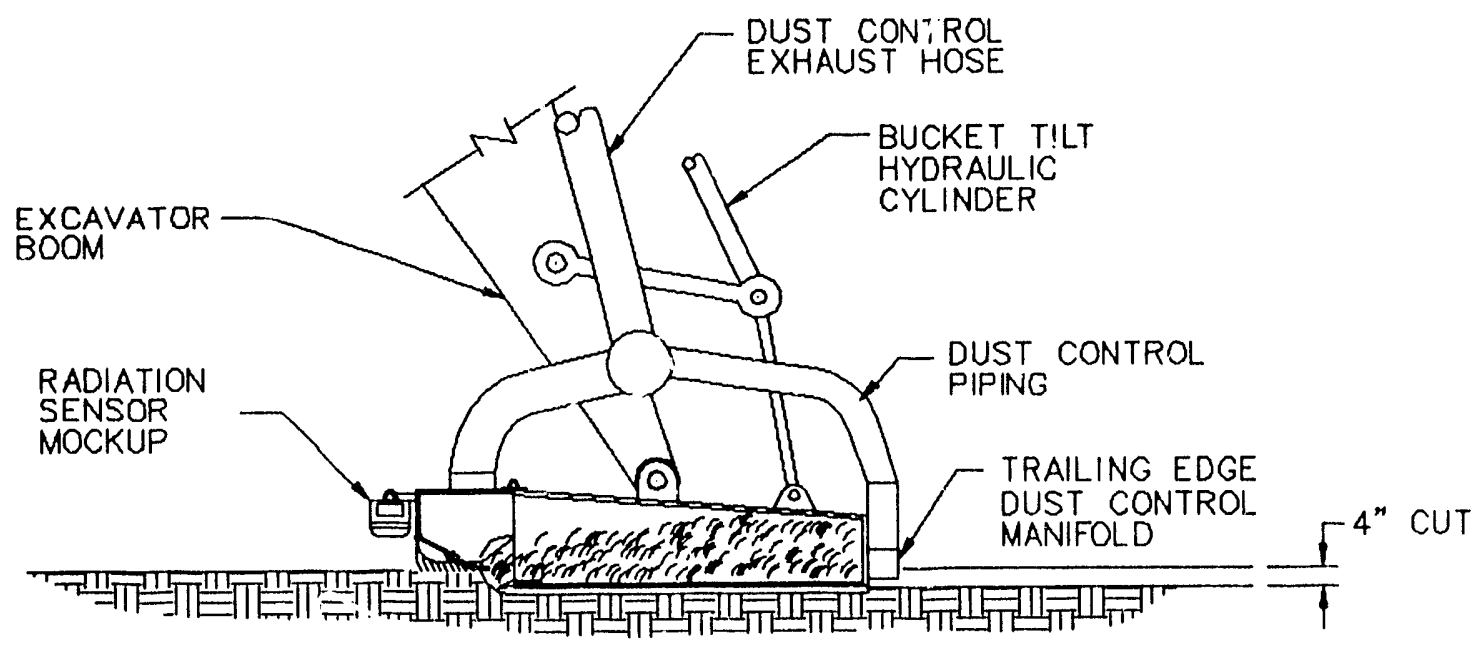

OVERBURDEN REMOVAL OPERATION

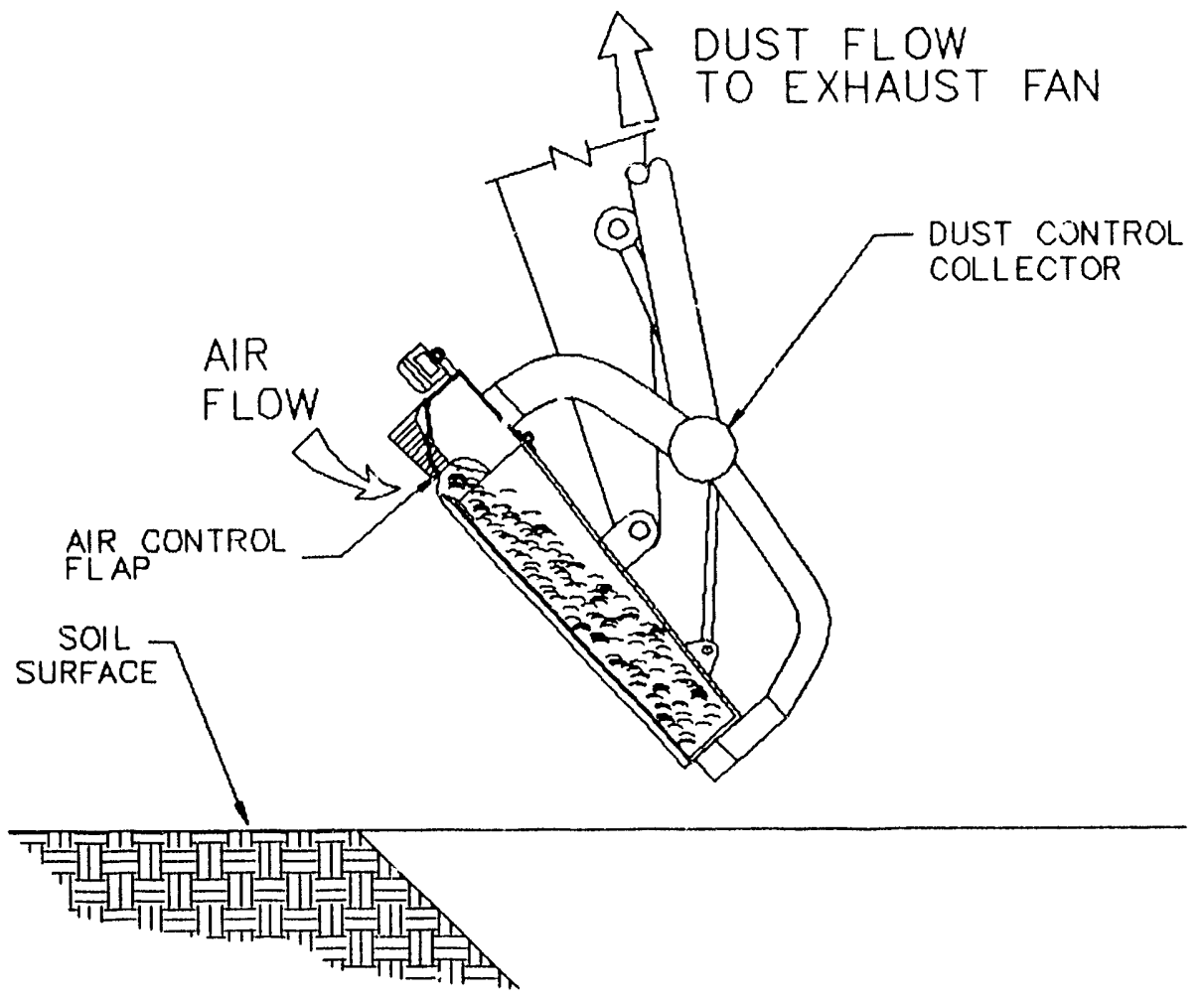

BUCKET LIFTOFF FROM SOIL SURFACE

FIgure 18. The excavator bucket has bern designed to minimize soil disturbance. Spillage is avoided by ending each stroke at the pit ivall and tilting the bucket. to follow the wall, thereby allowing the soil to fall back into the bucinet. 


\subsubsection{Mock Radiation Sensors}

As shown in Figure 18, mock radiation sensors are mounted on the bucket ahead of the disturbed soil. For a hot pit application, functional sensors would be mounted here and connected to an alarm in the operator's cab. For this demonstration, only visual reference data can be gathered for these sensors because they will be dummies with no output to monitor. On a hot application, sensors on this bar would provide an immediate alarm if the type and intensity of radiation vere sufficient for detection. Floating sensor mounts and steel guards around the sensors protect them from damage by rocks or other obstructions.

\subsection{Particulate Sample Filters}

Air sampling shall be performed using HI-VOL and LO-VOL particulate air samplers. The HI-VOL samplers (see Figure 19) contain a 4-in. air particulate filter that is held in the sampler by a screw-in retaining ring. The sampler unit is self contained with the pump, filter, and flow monitor. Air flow through the sampler is set to run at 10 to $20 \mathrm{cfm}$. The particulate air samplers will be positioned at several locations at the Cold Test Pit. The preweighed particulate filters will be removed from their petri dish, placed in the filter holder, and the retaining ring attached. The filter number shall be noted : $n$ the logbook along with the sampler location. The particulate filter is then ready for sampling.

The LO-VOL samplers consist of a sampler base, filter holder, and retaining ring as shown in Figure 20. The retaining ring holds the LO-VOL particulate filter in place in the filter holder. The filter holder is screwed in place to the sampler base at the sample location. The filter is then ready for sampling. All of the LO-VOL samples will be connected to rotary vane vacuum pumps located at the instrument shelter. The flow is regulated through each sampler by valves located in the instrument shelter. The flow through each sampler is measured using electronic mass flow sensors. The output from each sensor is connected to a datalogger and portable computer for data storage. Power for the instrument shelter is supplied by a portable generator.

MSA cyclone samplers may be used in place of the LO-VOL samplers on the excavator if necessary. This situation may arise if excessive vibration from the excavator causes dust to be shaken out of the filter, or if the lines running to the LO-VOL samplers are too long or become entangled too easily. The MSA cyclone samplers consist of a filter holder, sampler body, and end cap. Air is drawn through the sampler by a portable battery operated pump. Air passes through the sampler opening. The interior of the sampler body is designed to create a venturi effect. The heavier, nonrespirable particles fall to the bottom end cap. The lighter, respirable fraction is drawn up and collected in the filter. Before sampling, a preweighed filter and end cap will be placed on the sampler body. A diagram of a completed sampler is shown in Figure 21. The completed sampler is connected by tubing to the sampling pump. The pump is factory calibrated to run at 2 to $7 \mathrm{lpm}$.

\subsection{Laboratory Instruments}

\subsubsection{Mass Measurements}

Sample weights will be obtained using either a Satorius balance, model AS120, or a Mettler balance, model AJ100. These balances weigh to the nearest 0.1 of a milligram. 


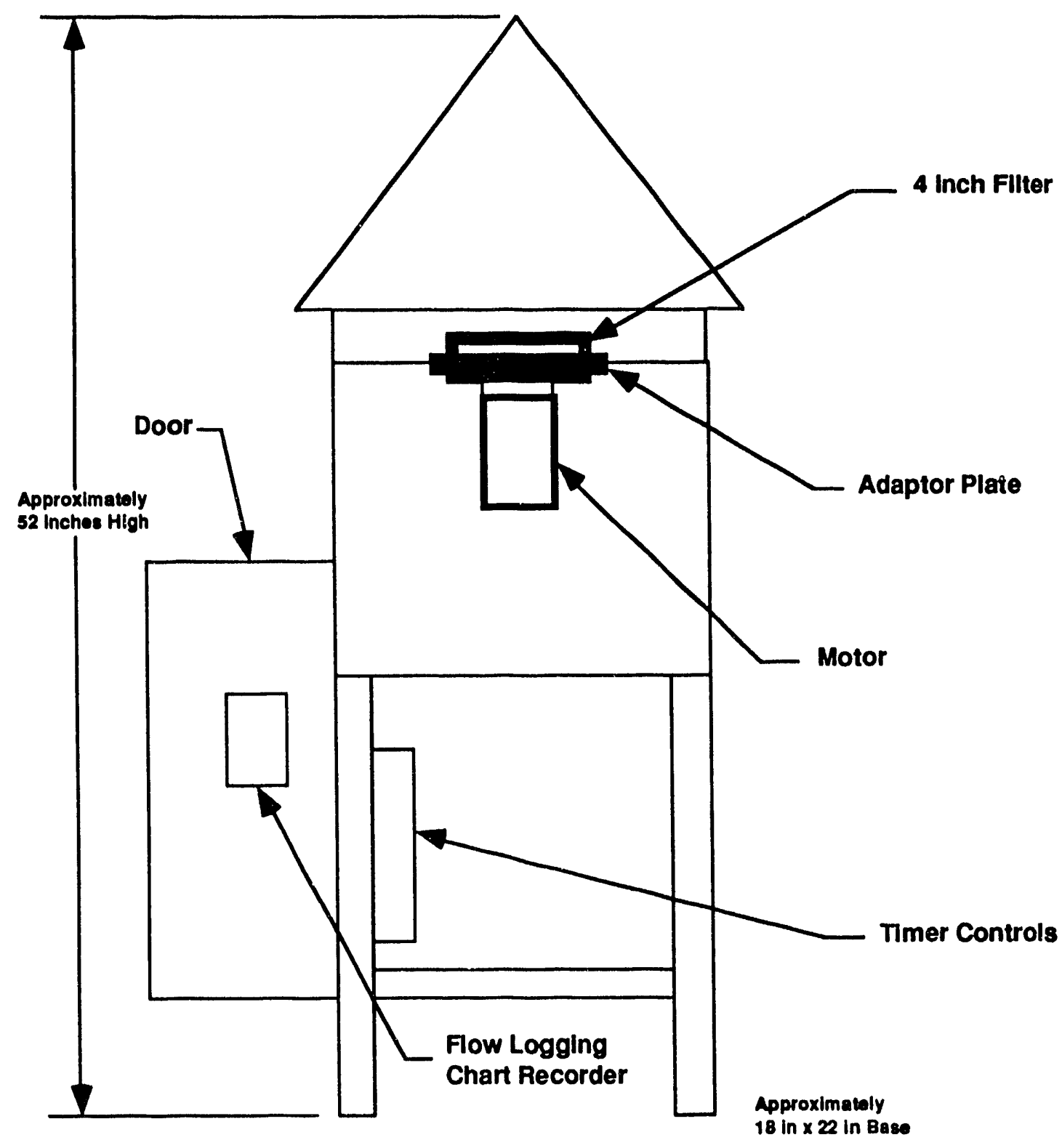

Figure 19. Cross sectional view of the HI-VOL air sampler. HI-VOL particulate air samplers will be used to determine background dust levels and monitor dust and contamination spread during the demonstration. HI-VOL samplers placed on the west side of the Cold Test Pit may require replacement in recesses to provide clearance for the excavator counterweight (approximately 41 in.). 


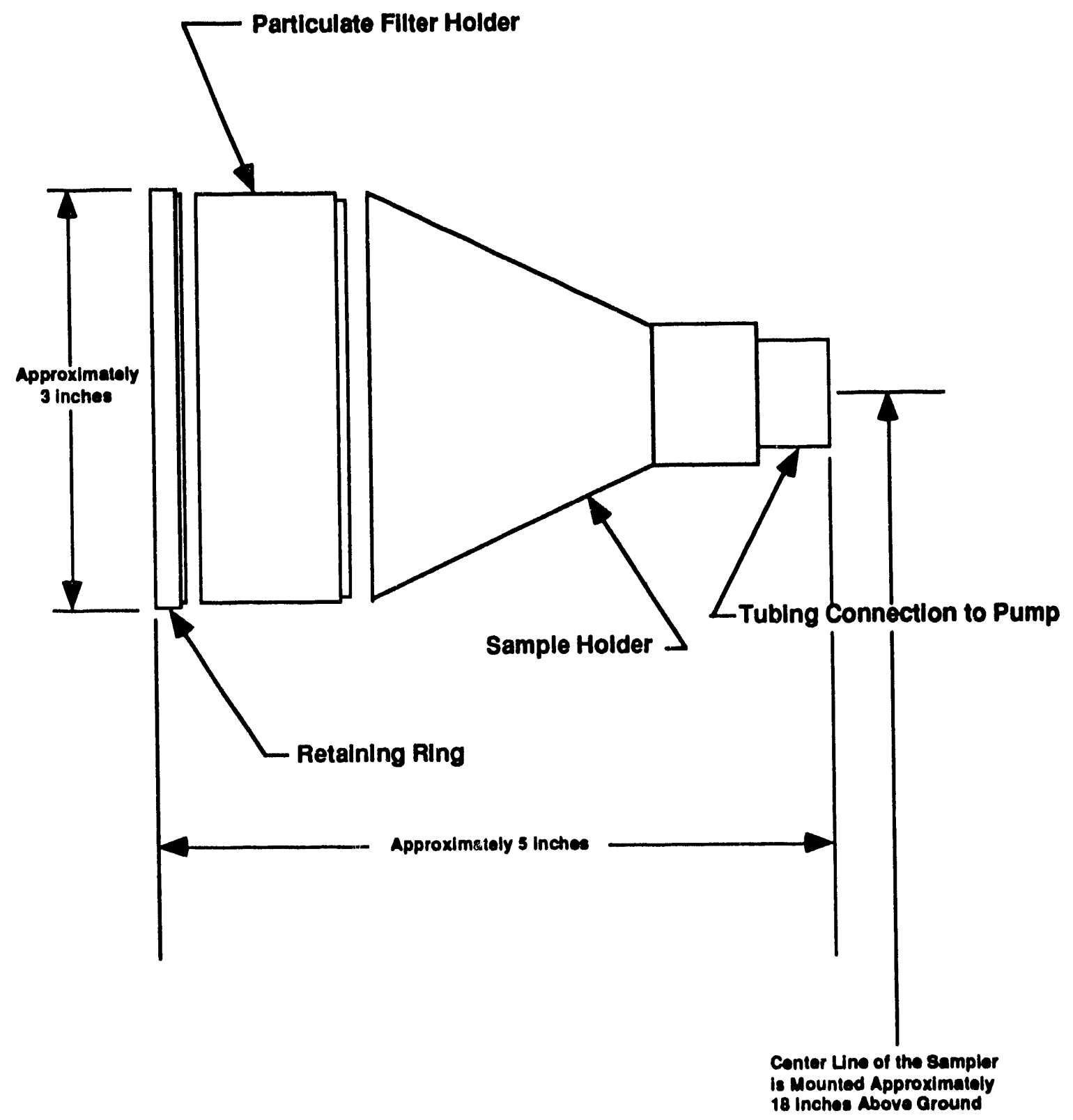

Figure 20. Forty-seven millimeter particulate air filters will be used to determine contamination spread and dust generation during the demonstration. 


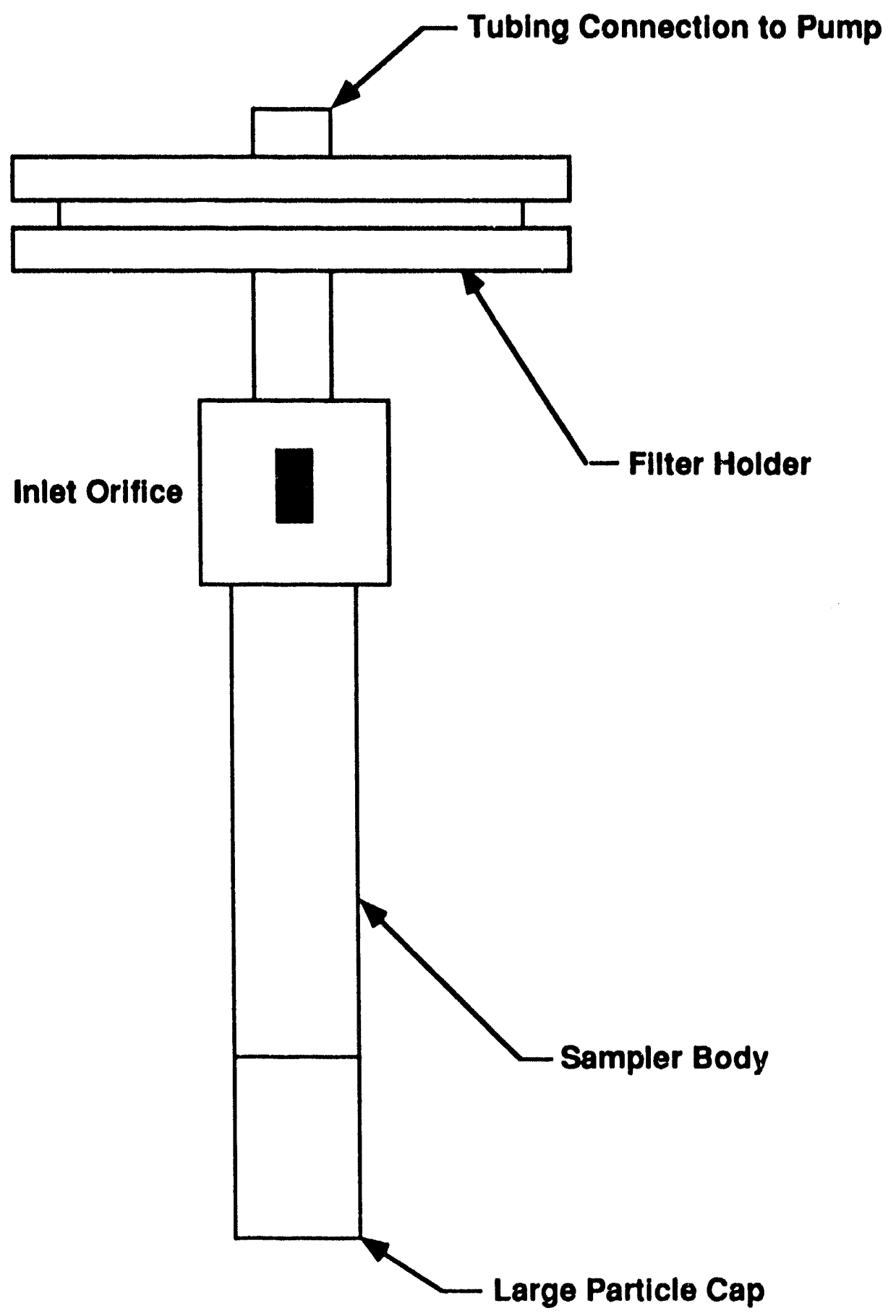

Figure 21. Diagram of MSA cyclone sampler. The filter captures respriable particles of 10 to $20 \mu$ in size. Larger particles are separated out and fall to the bottom of the sampler. Cyclone particulate air samplers may be employed if necessary in place of the $47-\mathrm{mm}$ samplers on the excavator. 


\section{TEST PROCEDURES}

The removal of soil overburden concept for contaminated pits and trenches involves using equipment that will remove a small layer of soil at from 3 to 6 in. at any time. As soil is removed in layers, a sampling team will collect soil samples for rapid ridiochemical analysis for TRU contaminants. Using this method, a layer can be considered free from contamination, and removal of the next layer of soil in the overburden area can begin. It is generally expected that no contamination will be found in the soil overburden. This soil was brought in after the waste was put in place. Although it is anticipated that some containers in the waste zone have lost their integrity, the waste leakage from those containers has migrated gravimetrically downward into the waste zone. However, to maintain a safe work environment, this method of removal should allow the safe preparation of a pit or trench for final remediation.

The BWID Program has contracted vendor services to provide equipment and techniques to demonstrate soil overburden removal technology. The demonstration will include tests evaluating equipment performance and techniques for removal of overburden soil and control of contamination spread and dust. To evaluate the performance of these techniques, air particulate samples, physical measurements of the excavation soil cuts, maneuverability measurements, and time versus volume (rate) of soil removal data will be collected during removal operations. To provide a medium for sample evaluation, the overburden will be spiked at specific locations and depths with rare earth tracers. The following sections will describe the methods to be used to operate the equipment and use the techniques in the test area; the methods to be used in collecting samples to analyze for rare earth tracers during the demonstration.

\subsection{Preparation}

BWID shall provide communications, sanitary facilities, water, office trailer, and generators as specified in the Buried Waste Integrated Demonstration FY-93 Deployment Plan. BWID shall also provide access to the Cold Test Pit and ensure that the area is available for testing. BWID shall also ensure that the Cold Test Pit has been restored and recontoured following any previous tests.

Before mobilizing to the site, the boundary of the Cold Test Pit will be surveyed and marked. In addition, the area of the Cold Test Pit to be spiked with rare earth tracer (see Figure 4) shall be surveyed and marked.

\subsubsection{Mobllization}

Sonsub will offload all equipment and stage in a safe area as indicated by EG\&G ldaho. Sonsub and EG\&G Idaho personnel shall attend a safety kickoff meeting to be conducted by BWID before any site operations. Sonsub will begin the test procedure based on the survey stakes placed by EG\&G Idaho, locating the Cold Test Pit area.

\subsubsection{Alr Sampling Methods}

The Cold Test Pit overburden shall be spiked with rare earth tracer materials to provide a casy method to analyze and evaluate samples. The samples shall be analyzed to determine the ability to minimize the generation and resuspension of fugitive dusts during soil overburden removal operations. Each test will have a known amount of rare earth tracer placed at strategic locations within the overburden. The tracer shall be placed into the ground in bore holes drilled in a grid paltern to a depth of $5 \mathrm{ft}$. Figure 4 shows the layout of the grid pattem.

The bore holes shall be filled completely with a mixture of predried, screened soil and tracer. The soil shall be predried to $<4 \%$ moisture by weight and screened using a $2-\mathrm{mm}$ mesh sieve to remove any large soil particles. The soil will then be mixed with tracer at a level of at least 10 times greater than the background level of that tracer. The tracer to be used is erbium. The tracer is commercially available in the form of oxide powders and characterized for particle size. 
The primary analytical method will be to collect air particulate samples at strategic locations within and around the test area. Air particulate samples shall be collected using HI-VOL 4-in. samplers (10 to $20 \mathrm{cfm}$ flow rate) and LO-VOL $47-\mathrm{mm}$ samplers (2 to $5 \mathrm{cfm}$ flow rate). These samplers will be located around the excavation area and on the excavation vehicle. The samples will be used to determine the tracer air concentration caused by equipment operations in the test area. The samplers will be located upwind and downwind of the immediate test area to determine the degree to which any tracers will migrate.

Samples shall be analyzed for rare earth tracers using the Inductively Coupled Plasma-Mass Spectrometry (ICP-MS) method by the EG\&G Idaho Environmental Chemistry Unit. Samples and data shall be analyzed using methods used in previous tracer sampling studies conducted at the Cold Test Pit.

\subsection{Precautions}

\subsubsection{Environmental Conditions}

During the overburden removal tests, wind direction, wind velocity, temperature, humidity, and barometric pressure shall be recorded. However, under specific conditions, the data may no longer be useful. For example, if the wind direction changes past a certain range, the monitors will not be sampling at the appropriate locations, or if the wind velocity excecds a certain amount, the amount of dust measured will not represent what the equipment is generating. If the humidity rises, it can act as a contamination control method. This type of data would be useful for the USID Program. Wind velocity, temperature, humidity, and barometric pressure will be monitored and recorded continuously by National Oceanic and Atmospheric Administration (NOAA) from the RWMC weather station. NOAA will record and provide the data separately. These data are extremely voluminous, and there is no practical way to record these data in the logbooks. NOAA will provide archiving and data reduction.

The following criteria have been set so that testing will be terminated if the environmental conditions exceed the values. NOAA continuously monitors environmental conditions at multiple locations across the INEL, including the RWMC. NOAA has agreed to contact the program if any of the criteria are exceeded and provide continuous environmental data.

\section{Phase I Testing}

1. If the continuous wind direction is not within the wind rose range identified in Figure 22 , the tests should be terminated until the wind changes back into tolerance.

2. If the continuous wind speed exceeds $15 \mathrm{mph}$, or at the discretion of the field test personnel, the tests will be terminated until the wind has subsided. Test runs and air samples may be repeated at the discretion of the EG\&G Idaho site representative 10 account for metcorological disturbances.

\section{Phase II Testing}

1. If the continuous wind direction is not within the wind rose range as identified in Figure 22 , or at the discretion of the field test personnel, the tests should be terminated until the wind changes back into tolerance.

2. If the continuous wind speed exceeds $15 \mathrm{mph}$, or at the discretion of the field test personnel, the tests will be halted and new filters placed in the particulate dust monitors. The test will be resumed with dust data taken at the higher wind velocity. Test runs and air samples may be repeated at the discretion of the EG\&G Idaho site representative to account for metcorological disturbances. 

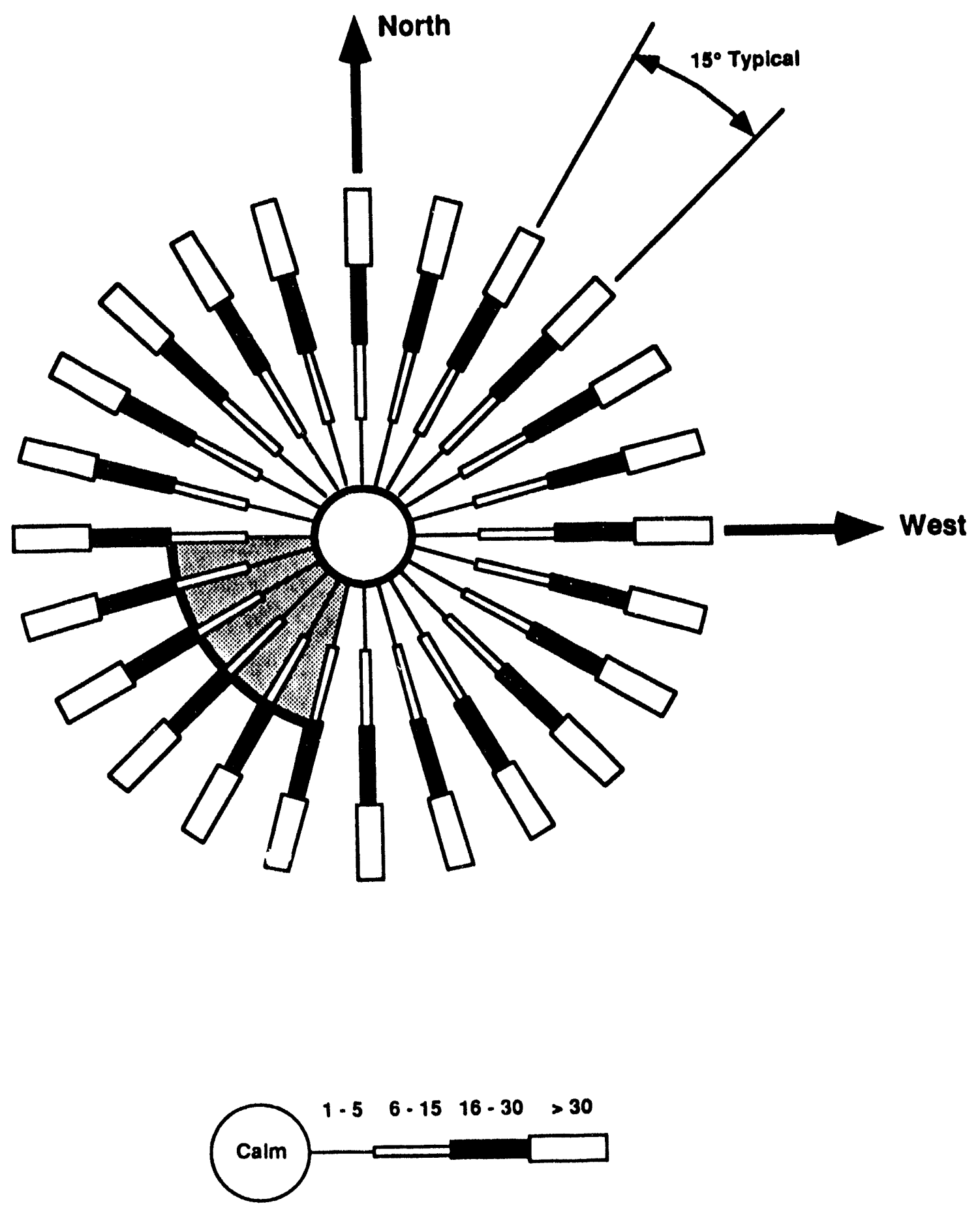

Figure 22. The shaded zone in the above wind rose indicates the go-zone for performing contamination analysis dust collection. The allowable wind speed is $15 \mathrm{mph}$ maximum, and the allowable wind direction is from the west and southwest as indicted. 
Phase II Testing

1. No dust or contamination spread measurements will be taken during this phase of the test because of the cquipment and soil dumping that are located upwind of the Cold Test Pit. Also, this test series will not be restricted on wind velocity and direction as the previous two phases, except for health and safety rcasons.

The average high temperature at the Central Facilities Arca (CFA) in August is $71^{\circ} \mathrm{F}$. The highest daily maximum recorded at CFA in August was $100^{\circ} \mathrm{F}$, and the lowest daily minimum was $28^{\circ} \mathrm{F}$. The average number of freeze/thaw cycles in August at the CFA was 2 with a maximum number of 16 and a minimum of 0 .

In August, average sunrise time at CFA is approximately 5:37, and sunset is 7:35 Mountain Standard Time.

The average total precipitation in August at CFA is .55 in. with a maximum of 3.27 in. and a minimum of $0.00 \mathrm{in}$. The average number of days (\%) on which precipitation was recorded at CFA in August is $21 \%$ (trace or more), $12 \%$ ( 0.01 in. or more), $5 \%$ (0.10 in. or more), $1.0 \%(0.50$ in. or more), and $0.0 \%$ (1.0 inch or more). In August at CFA, $86.8 \%$ of the time the ground surface is dry; $7.5 \%$ of the time the ground surface is moist (c.g., dew); and $5.7 \%$ of the time the ground surface is wet (c.g., standing water in small or large pools at the surface).

The average relative humidity in August at CFA is $31 \%$. The average maximum relative humidity is $65 \%$, and the minimum is $15 \%$. The absolute maximum relative humidity is $100 \%$ and minimum is $4 \%$.

At CFA, the average atmospheric pressure in August is 25.09 in. of mercury. The average maximum atmospheric pressure is $25.15 \mathrm{in}$. of mercury and minimum is $25.03 \mathrm{in}$. of mercury. The absolute maximum atmospheric pressure is $25.37 \mathrm{in}$. of mercury, and the minimum is $24.72 \mathrm{in}$. of mercury.

\subsubsection{Laser Transmitter}

Each moming the laser transmitter will be set on its tripod, which will be sand bagged. The area around the transmitter will then be roped off with high visibility safety ribbon to prevent bumping or tampering.

\subsubsection{Weather}

Excessive wind or rain may cause delays in the demonstration. The Sonsub project manager and/or project engineer and EG\&G Idaho site representative will be responsible for making the decision to delay. Test runs and air samples may be repeated at the discretion of the EG\&G Idaho site representative to account for meteorological disturbances.

\subsubsection{Excavation}

As the excavation of the pit deepens, special altention will be given to the possibility of breaking into the waste below. If this happens, the EG\&G Idaho site representative will decide how to proceed.

\subsection{Test Procedure}

The soil overburden shall be removed from the Cold Test Pi! by Sonsub and their respective equipment and techniques as detailed in this test plan. EG\&G Idaho shall perform the dust and contamination spread monitoring and analysis.

Listed below is an general procedure for operations during the demonstration. For a more detailed procedure, refer to the Appendix $A$. 


\subsubsection{Mobllization}

1. Set up the particulate air samplers, pump house, and generator as shown in Figure 7. Ensure proper flow rates are being attained confirm operation of the data loggers and operation of the pump house. Install soil moisture cells at depths of appmximately 3,4 , $6,12,16$, and 20 in. in an area adjacent to the Cold Test Pit that will not interfere with test operations.

2. Hold safety kick-off meeting at the Cold Test Pit with RWMC Safety Engineering. Review all precautions and procedures to ensure a safe work site. Ensure safety equipment is available, and everyone is instructed in its proper use.

3. Briefly review the test plan and sequence of events.

4. Unload and stage all equipment at the site being cautious not to disturb the Cold Test Pit area.

5. Using a transit, install the sighting lines at the side and end of the pit to use for locating the depth measurement grid points for both the Phase I and II tests.

6. Set up the laser grade control system. Complete the contour map of the pit as shown in Figure 6.

7. Connect the hoses and distribution for the dust control system from the excavator. Connect electrical cables from the blower to the generator.

8. Connect the LO-VOL air samplers to the excavator.

9. Using the excavator with the bucket set for a 6 -in. cut, remove the high points on the castem half of the Cold Test Pit to provide a flat datum plane of at least $10 \times 40 \mathrm{ft}$. This zone must lie within the boundary of the portion of the pit that is spiked with the rare earth tracer as indicated in Figure 4. At the end of each strip, rotate the excavator 186, degrees and dump the soil being careful to generate as little unnecessary dust as possible.

\subsubsection{Phase I}

1. Obtain 30 minutes worth of background data from the HI-VOL samplers, then pull the background sample filters and replace with new filters.

2. Using the sighting lines as guides and laser transmitter as a flat plane reference, use a laser receiver on a graduated survey mast to establish and record the height readings across the 30 point grid and measure any breaks or steps at the edges of the cuts.

3. Start the LO-VOL and HI-VOL filters.

4. Set the excavator bucket for a 3 -in. cut. Remove a 3 in. deep layer of overburden from the complete flat datum plane area.

5. When removal of the soil layer is complete, shut down the particulate air samplers, and remove and replace the filters (LO-VOL and HI-VOL).

6. Repeat Step 2 to measure the actual soil removed at all 30 points within the $10 \times 40$-ft test area and establish a datum for the next cut.

7. Repeat Steps 1 through 5 with the excavator bucket set for a 4-in. cut.

8. Repeat Steps 1 through 5 with the excavator bucket set for a 6-in. cut. 
9. Repeat Steps 1 through 5 taking two 6-in. cuts to total 12 in. before taking the depth readings.

10. Verify that all readings are properly recorded. This completes the Phase I test phase.

\subsubsection{Phase II}

1. Obtain 30 minutes worth of background data from the HI-VOL samplers, then pull the background sample filters and replace with new filters.

2. Using the sighting lines as guides and laser transmitter as a flat plane reference, use a laser receiver on a graduated survey mast to establish and record the height readings across the 50 point grid required for the Phase II test.

3. Mark off a $10 \times 10$-ft area in the middle of the pit 10 represent an obstacle to be excavated around.

4. Set the excavator bucket for a 3, 4, or 6-in. cut to be determined at the end of Phase 1 . This setting will be used for the remainder of the demonstration.

5. Reconfigure the location of the air filters as illustrated in Figure 10 and insen new filters for dust measurements. Tum on the pumps and monitor wind conditions.

6. Start at the south end of the pit operating from the east side. Begin taking 3, 4, or 6 in thick $\times 3 \mathrm{ft}$ wide strips of soil. At the end of each strip, rotate the excavator 180 degrees and dump the soil being careful to generate as little unnecessary dust as possible.

7. As the excavator moves down the length of the pit, begin taking actual cut depth measurements at the grid locations using the laser system. Record all measurements. Operation of the excavator must be coordinated with EG\&G Idaho personnel laking air samples. Take at least 10 soil moisture probe readings at random locations throughout the area of soil to be removed. The depth at which the reading will be lake'll shall be one-half of the depth of soil to te removed in the next increment.

8. When the excavator reaches the end of the pit, having completed one pass, it should returm to the south end and start a second pass. Continue taking cuts over the test area down to a $6 \mathrm{ft}$ maximum depth.

9. Verify that all readings are properly recorded and sufficient data have been gathered to the satisfaction of the EG\&G ldaho site representative. This completes the Phase II test.

\subsubsection{Phase III}

1. Relocate the excavator to the western side of the Cold Test Pit.

2. Take as many cuts as necessary to establish a flat datum on the top of the pit using the laser system as is reference.

3. Begin taking 3, 4, or 6 ill. thick $\times 3 \mathrm{ft}$ wide strips of soil traversing down the length of the pit and back. The object is to establish a measurable production rate for this process with no delays. Record all data.

4. As the excavator moves down the length of the pit, begin laking actual cut depth measurements at the grid locations (see Figure 14) using the laser system. Record all measurements. 
5. When the excavator reaches the end of the pit, having completed one pass, it should retum to the south end and start asccond pass. Continue laking cuts over the test area down to a 6 fi maximum depth.

6. Verify that all readings are properly recorded and sufficient data have been gathered to the satisfaction of the EO\&O Idaho site representative. This completes the Phase III Iest.

\subsubsection{Cold Teat Plt Restoration}

1. At the completion of this test, remove all markers and other liems from the slie. Use the bulldozer and excavator to restore the site to an as found condition.

2. Demobilize all equipment and personnel from the site

\subsection{Data Analysis}

Data taken during these lests shall be recorded on previously prepared forms for consiatency. All data shall be reviewed on a continued basis by the Sonsub project manager or project engineer and the EG\&C Idaho site representative. If the data reflect inconsistencles or other unforeseen occurrences, agreement can be made to nepeat portions of the test of change the operating criteria of the lest.

ECi\&O Idaho shall record all dust and meteorological data. Sousub shall record all volume. time, and depth measurements related to the soil removal.

NOAA will provide continuous metcorologl al dala obtained from the RWMC station. All datia shall be lime stamped so that if can be associated with the NOAA environmental data.

All raw and final data, including laboratory notebooks, will be incorporated into the BWID dalta management system. 


\section{SAMPLE CONTROL. AND DOCUMENT MANAGEMENT}

This section discusses document control. LCi\&(i Idaho procedures for control shall be followed for this project.

\subsection{BWID Requirements}

Datw shall be inanaged in the manner that best protects the credibility of the data and is in compliance w/th the BWID Project Management Plan. In addition. the principle investigator shall comply with the following BWID data management policy.

\subsubsection{Management of Electronle Data}

- The principle investigator shall define the format, acquire the data, back up the data on a dally basis, control the configuration of the data, technically document the dala, generate processed data, and archive the dala.

- The principle investigator shall submil to BWID a copy of all configuration controlled data (raw and processed) and appropriate lechnical documentation acquired during the course of the demonstration lesting. The project shall submit complete coples of final configuralion controlled raw and processed data with appropriate technical documentation to BWID with the final repun.

\subsubsection{Management of Reports}

- The principle investigalor shall drall reports, obeain und incorporate review comments, oblain approvals. archive, and comerol the configuralion of data via a project linginecring Design File.

- Copies of all drall repons shall be submilled II BWII) (oples of all final reports shall be subinitied to (SWII) with an elecininic copy.

\subsubsection{Management of Logbooks}

- Dala shall be recorded in logheosks in accordance with Ee(i\&(i ldallo guidelines. A dala loghook will be kepl during sel up and conduct of experiments As a minimum, specific: data that shall be included in lle loghook for the work performed under this test plan are listed below:

- Locations of samplen during all lests

- How meter calibration information

- Computer and selup information

- Now rales

- Computer informatton including run identifiers, stan times, disk file Identifiers, and data storage inlommatlionl

Filler and smear pre and pont-weights

- Changes made in experimential or electronic presets

- Test abnormalities observed

Date and negalive numbers of any photographs laken

- Dales and inlormation on all qualliy assurance samples (standards, blanks, and duplicilles)

- Manufacturer and medel number of laxer trallsmiller

- Depili measuremeniss of exciavallonll culs

- Mancuverabilily mesisurements

- Lexcavation proceres parantelers (lime, velume, lengeth of cue, eles)

- Unusual eventis

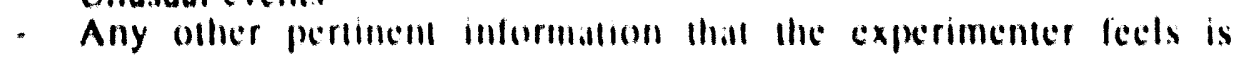
necensary. 
In addition, cach page and entry into the loggteok shall I e dated and coded with the name of lie person making the entry.

- All logbook entries shall be pholocopied al the elid of each day of the demonstration and copies delivered (o) BWID.

\subsubsection{Management of Samples}

- Sample control will be maintained by placing all filiers and smears in an numbered petri dish after the initial weight is recorded using the system indicaled below:

Sample ID $=\mathbf{P} \cdot \mathrm{X}$

whene

$$
\begin{aligned}
& P=\text { paniculate air filler } \\
& X=\text { alpha numeric sample number. }
\end{aligned}
$$

- When that simple is used during lesting, all pertinemt data for that sample will be noted in the loghook. In addition. plot plans will be used to give a reference to each sample localion to nole the location and lest pirameters of each simple taken. These plots will be included as inserss in the loghook. Fach insert will be signed and dated.

- A chain of custody form will be prepared for each sel of samples collected before iranslerning the samples to the antalytical latxoratory for tracer analysis.

\subsection{Video Production}

A video shall te taken of the overthurden removal demonstration at the Cold Test Pit. The purpese of the video is 1 ) document the demonstration and provide qualitative data on performance of the sysiem. The video may also be used to validate or collect data for time-motion parameters of llic les.

\subsection{Data Reporting}

To ensure that the demonstration results are reported to interested partics, the following Ine lhods of data reporting will be used:

- Technology Livaluation Repon-The data generaled by the demonstration as well as the information on the planning and conducting of tests will be assembled and documented in a Technology Evaluation Report. The Technology Evaluation Repon will summarize the tests, lest results, and lessons learned and provide recommendations for further developmenti.

- Publications Information on the demonstrations and results will be submilted for publication to the Waste Management ' 94 conference and other waste management or environmential restoration related journals, conferences, and meetings.

- HWID Open House A public open house will be held by BWID on July 29 and 30, IOO3, (1) display BWID projects.

\subsection{Test Plan Changes}

Change requests 10 this plan may be initialed by any person panicipating in the overburden cemoval demonstration, but they must be approved by the principle investigator and/or the BWID project manager. (hanges that are determined by the principal investigator and project manager to 
be minor will be approvend and incorporated immediately. These changes shall be clearly documer.ed by red-lining the procedures to match the procedure that is actually followed, initialing the procedure, recording the changes in the daily logbook, and photocopying the procedure to be sent to BWID. Changes that are deemed to be significant by the principal investigator and project manager shall be succumented and approved by the BWID program manager. 


\section{EQUIPMENT}

Table 2 provides a list of equipment and supplies needed to conduct sampling during the overburden removal process. Table 3 lists primary equipment to be used for this dernonstration. The equipment noted as rental may be substituted with an equal or better depending on availability at the time of the demonstration.

\subsection{Maintenance and Operation}

Because of the shor duration of this demonstration, only the following maintenance should be performed. All of the following shall be performed each morning before starting the equipment.

- Check lubricant and coolant levels on the excavator, generator, and bulldozer

- Check diesel fuel levels on all of the above

- Check battery levels for the laser system

- Check dust control hoses or free passage; no obstructions.

\subsection{Calibration}

Air monitor calibration and all associated flow sensors is performed by the EG\&G Idaho Standards and Calibration Laboratory on a biannual basis. No calibration is necessary for the excavator, bucket, or dust control system.

All adjustments on the laser system are factory calibrated. The transmitter is manually set close to vertical by use of a built-in bubble level. The rotating laser transmitting head then self levels.

Table 2. Air sampling equipment, laboratory equipment and consumables (filters) are required to determine the contamination spread and dust generation of the overburden removal demonstration.

Description

Required

Anderson $\mathrm{HI}$-VOL samplers

Sartorius five-place analytical balance

3

4-in. glass fiber particulate filters

LO-VOL particulate samplers

Instrument shelter and portable generator

MSA cyclone samplers and portable pumps

Soil moisture analyzer

1

TBD

10

1 each

4 maximum

1

Table 3. With the exception of the custom excavator bucket, standard construction equipment will be used in performing the demonstration.

Description

Required

Caterpillar hydraulic excavator EL300B (rental)

Custom bucket assembly - approximately 1 yd capacity

$1700 \mathrm{cfm}$ high pressure blower-5 hp ac motor driven

8 in. diameter flexible duct hose

Catcrpillar D4 crawler bulldozer (rental)

Diecel generator (towable)-10 to $20 \mathrm{~kW}-1 \mathrm{Ph}$ or $3 \mathrm{Ph} \mathrm{AC}$ (rental)

Laser leveling transmitter

Laser receiver $w /$ mast for bucket

Laser receiver $w /$ graduated pole for manual

1

1

$200 \mathrm{ft}$

1

1

1 


\section{ANALYTICAL PROCEDURES}

\subsection{Gravimetric Analysis of Filters}

All filters (HI-VOL, LO-VOL, and MSA cyclone) shall be dried by desiccation before weighing to ensure that there is no excess moisture in the filter. All filters shall be weighed on a fiveplace analytical balance that has been calibrated and approved by the EG\&G Idaho Standards and Calibrations Laboratory. All filters shall be preweighed before transport to the Cold Test Pit to establish a baseline weight. The filter will then be placed in a petri dish and sealed until used at the sampling location. The sampler filter shall be handled using tweezers to minimize contamination of the filter from moisture or natural skin oils from the hand. The filter will be placed on the balance, and the initial weight recorded in the project logbook.

After sampling, the particulate filters shall be dried to remove any excess moisture trapped in the filter during sampling. The samples will then be taken to the weighing area and the filter placed on the balance. The weight will then be recorded in the project logbook. This procedure will be repeated for all filters. After all the filters have been weighed, the samples will then be transported for tracer analysis. The sampler filter shall be handled using tweezers to minimize contamination of the filter from moisture or natural skin oils from the hand. The filter will be placed on the balance, and the initial weight recorded in the project log book.

\subsection{Chemical Analysis of Filters}

The digestion method used for glass microfiber filters for lanthanide elements is fully described in the Analytical Chemistry Environmental Chemistry Laboratory (ECL) Standard Operating Procedure (SOP) IP-1.3. The fiiters are digested on a hot plate using nitric acid and hydrogen peroxide. The method is a hot acid leaching procedure and not a total digestion. While the method does not result in total dissolution of the glass microfibers, previous studies have shown that rare earths are fully dissolved by this method. After digestion the samples are analyzed by ICPMS. The determination of lanthanide elements by ICP-MS is described in the Analytical Chemistry ECL SOP IM-6.1. The specific rare earth element tracer analyzed for will be erbium.

\subsection{Calculation Procedures}

\subsubsection{Excavation Depth-of-Cut Analysis}

Data Quality Objective: Determine with a 95\% confidence level that for any target increment depth specified, the increment of soil removed (depth-of-cut) is no deeper than 1 in. below that target depth.

During the test, depth measurements will be taken to determine the precision and accuracy with which increments of overburden soil can be removed from a subsurface disposal pit or trench. Each $3 \mathrm{ft}$ wide strip, or cut, performed by the excavator is deemed to be an independent replicate. Thus, for each increment of soil removed in any phase of the test, at least five independent replicates exist. Calculations for determining precision and accuracy are as follows:

Precision (Standard Deviation): Average deviation of the observations from each other.

$$
S=\sqrt{\frac{\sum_{i=1}^{n}\left(X_{i}-\bar{X}\right)^{2}}{n-1}}
$$

where

$$
X_{i}=\text { an observation }
$$




$$
\begin{array}{lll}
\bar{X} & = & \text { the mean of the observations } \\
S & = & \text { the standard deviation (precision) } \\
n & = & \text { the number of observations. }
\end{array}
$$

Accuracy (Bias): Average deviation from the value expected.

Bias $=\frac{\sum_{i=1}^{n}\left(X_{i}-\mu_{0}\right)}{n}$

where

$$
\begin{array}{ll}
X_{i} & =\text { an observation } \\
\mu_{0} & =\quad \text { the target cut depth } \\
n & =\quad \text { the number of observations. }
\end{array}
$$

To assess whether the depth-of-cut exceeds the target depth, a t-test or similar statistical procedure may be employed. The procedure tests the hypothesis of equality of depth-of-cut to target depth (e.g., is depth-of-cut equal to the target depth?):

Hypothesis: Depth-of-cut $=$ target depth

Hypothesis: $\quad \mu_{m}=\mu_{o}$

where

$$
\begin{array}{ll}
\mu_{m} & =\text { the true mean of the depth-of-cut } \\
\mu_{o}= & \text { the mean target cut depth. }
\end{array}
$$

Then the one sample t-test is

$t=\frac{\bar{X}_{m}-\mu_{0}}{S}$

where

$$
\begin{aligned}
& \bar{X}_{m}=\text { the observed mean of the depth-of-cut } \\
& S=\text { the standard deviation. }
\end{aligned}
$$

\subsubsection{Dust Measurement Analysis}

Data Quality Objective: Determine with a $95 \%$ confidence level that dust generation was detected at levels 10 times above background level. 
To assess whether the dust generated during soil removal exceeds the background level of dust, a t-test or similar statistical procedure may be employed. The procedure tests the hypothesis of equality of the dust detected during operations to background dust levels (e.g., is dust detected on the air sample filters equal to the background level of dust?):

Hypothesis: Dust detected = background dust

Hypothesis: $\quad \mu_{d}=\mu_{b}$

where

$$
\begin{aligned}
& \mu_{d}=\text { the true mean of the background } \\
& \mu_{b}=\text { the true mean of the dust detected. }
\end{aligned}
$$

Then the two sample t-test is

$t=\frac{\bar{X}_{d}-\bar{X}_{b}}{S_{\text {Pooled }}}$

where

$$
\begin{aligned}
& \bar{X}_{b}=\text { the observed mean of the background } \\
& \bar{X}_{d}=\quad \text { the observed mean of the dust detected } \\
& S_{\text {Pookd }}=\quad \text { the pooled standard deviation. }
\end{aligned}
$$

\subsubsection{Rare Earth Tracer Analysis}

Data Quality Objective: Determine with a 95\% confidence level that the rare earth tracer (erbium) was detected 10 times above background level.

To assess whether the rare earth tracer detected on the air sample filters exceeds the background level of rare earth tracer, a t-test or similar statistical procedure may be employed. The procedure tests the hypothesis of equality of the rare earth tracer detected during operations to background rare earth tracer (e.g., is rare earth tracer detected on the air sample filters equal to the background level of rare earth tracer?):

Hypothesis: Erbium detected = erbium background

Hypothesis: $\quad \mu_{d}=\mu_{b}$

where

$$
\begin{aligned}
& \mu_{d}=\text { the true mean of the background } \\
& \mu_{b}=\text { the true mean of the erbium detected. }
\end{aligned}
$$


Then the two sample t-test is

$t=\frac{\bar{X}_{d}-\bar{X}_{b}}{S_{\text {Pooled }}}$

where

$\bar{X}_{b}=$ the observed mean of the background

$\bar{X}_{d}=$ the observed mean of the erbium detected

$S_{\text {pookd }}=$ the pooled standard deviation. 


\section{DATA MANAGEMENT AND ANALYSIS}

\subsection{Reduction, Validation, and Recording}

The data will be assembled, analyzed, and documented in EG\&G Idaho informal reports. Validation of the data will be ensured by following this document. Qualification of the data will be conducted by the analysis team and approved by the analysis team leader. Specific data reported include

- Measurement of mass of dust collected on filters

- Measurement of the amount of erbium collected on filters

- Depth of increments of soil removed

- Ambient environmental conditions during testing (wind velocity, temperature, and humidity)

- Dimensions for determining maneuverability of the excavator and the end-effector

- Soil moisture.

\subsection{Data Calculations}

During the overburden reınoval tests, the total airborne dust collected with the air samples will be used to compare the cmount of dust generated and contamination spread with the background levels. The total mass of dust on each sampler filter will be divided by the total volume of air sampled to determine airborne dust concentrations. The digestion method described in Section 8.2. will be used to determine the amount of erbium in the filter samples.

Depth-of-cut measurements will be taken during the tests and used to calculate the precision and accuracy of the soil removal. The mean and standard deviation of the data will be calculated to determine the precision and accuracy as is shown in Section 8.3.1.

The methods described in Section 8.3 are the general outline of the analysis plan; however, it is impossible to make the final determination on exactly how the data calculations will be executed until the data are available. The statistical analysis can become very complex; therefore, this test plan will not attempt to describe all the variations that the analysis may take. A complete and thorough discussion of the analysis and statistics used will be included in the final report.

Data will be provided and archived on the BWID data management system. 


\section{QUALITY ASSURANCE}

The quality level for this work scope will be Quality Level B. Quality of acquired data will be verified using a quick look review by the responsible EG\&G Idaho site representative, Sonsub project engineer or project manager, project scientist, and or other BWID Program personnel who are knowledgeable of data, assumptions, methodology, and individual measurements analysis to verify that data are within the performance specification as detailed in this test pian.

All testing shall be done in accordance with an approved test plan, approved test procedures, and with qualified personnel (as defined in the procedures). The test procedures shall specify sensor and measurement systems to be used (model number, make, calibration, etc.). Measurement uncerainty for data taken against the test objectives shall be documented.

\subsection{Depth-of-Cut Measurements}

A professional land surveyor will oversee the measurement of the soil depth-of-cut measurements. The professional land surveyor will approve the processes and procedures used to collect the data and perform periodic inspections to ensure procedures are being followed.

\subsection{Dust and Contamination Measurements}

Quality assurance of samples collected will be verified using several methods. All filters used for sampling will be weighed on a balance having a current calibration certification from the Standards and Calibrations Laboratory. Mass flow sensors or flowmeters will have current calibrations and calibration data from the Standards and Calibrations Laboratory before use. The calibration information will be referenced in the project logbook, and the reference data will be kept in the project file. Analytical results will be verified by the use of prepared standards, use of duplicate samples, and submission of blanks with each sample set. The standards, duplicates, and blanks will be submitted as a blind to the analytic laboratory.

The quality level for this work scope will be Quality Level B, as described in the Science and Technology Department's Quality Program Plan - 060. The analytical quality control will consist of the preliminary interference study to determine if other interfering elements or polyatomic species present problems during ICP-MS analysis for the two rare earth tracers. Included in each batch of samples (14 to 16 samples) will be a minimum of two blank filters from the same batch used for sampling, two air filters spiked with known quantitics of rare earth tracers, and a reagent blank for a reagent impurity check. Instrument batch quality control samples will consist of an independent calibration standard check and continuing calibration standard and blank checks every 10 samples. A post-digestion spike also will be included in every instrument batch. These quality control samples will provide precision and accuracy estimates for the analytical methodology.

Previously the laboratory has participated in analyses of rare earth tracers in support of the cryogenic retrieval demonstration during the summer of 1992. The analytical methodology is described in existing laboratory SOPs for this work; the only change to the SOPs for this work scope is the identity of the tracer analytes. In 1992, this laboratory was approved by EG\&G Idaho Environmental Restoration Department, Sample Management Office for analytical support of the cryogenic retrieval demonstration using these specific analyses.

\subsection{Field Monitoring and Maintenance}

Routine monitoring will be needed during the time that the samplers are operational in the field. During this check, the person will ensure that each sampler is operational and running within operational limits of the flow. Any changes made to the sampler shall be noted in the field logbook, along with any other information such as temperature, humidity, and weather conditions. In addition, the person shall conduct a routine safety inspection of the equipment and general area to ensure that no unsafe conditions occur. 


\section{SAFETY, TRAINING, AND LOGISTICS}

Safety is of utmost concern with all experiments. It is the policy of EG\&G Idaho to take every practical precaution to protect the health of the employees. Three types of safety and training concems are emphasized: radiological, laboratory, and waste management.

\subsection{Radiological Safeiy and Training}

No work involving radioactive materials will be conducted during this sampling.

\subsection{Laboratory Safety and Training}

Laboratory safe practices are described in the Science and Technology Standard Practices Manual, Section 2. Subsections of the standard practices that apply to this test plan include

- 1.5-Eye Protection and Protective Clothing

- 1.6-Laboratory Safety

- 1.8-Laboratory Hood Usc.

\subsection{Waste Management Practices and Training}

Waste management practices are prescribed in the Safety Manual, Section 15 and Science and Technology Standard Practices Manual, Section 2. Subsections of standard practices that apply to this test plan include

- 1.1-Non-Radioactive Chemical Waste Disposal

- 1.3-Chemical Lab Inventory

- $\quad 1.4$ Chemical Spill Control

- $\quad 2.9-$ Handling and Storage of Hazardous Waste in Satellite Accumulation Arcas.

Pertinent Safety Manual waste management practice subsections include

- 15.1-Routine Solid Waste Collection and Handling.

\subsection{Field Safety}

The RWMC safety engineer shall conduct a safety walk-down of the test area periodically but at least once a week. Safety discrepancies and concerns shall be reported to the Sonsub ficld supervisor and BWID site representative. Together, they shall act to correct any safety concerns that arise in a timely manner.

The following safety training is required:

- RWMC access training (available continuously at the gate house)

- BWID safety meeting (safety kick-off meeting on first day).

The following safety equipment will be required:

- Safety shocs

- Leather gloves for handling and moving equipment 
- Hard hats

- Hearing protection

- Eye protection with side shields. 


\section{RISK ANALYSIS}

The demonstration will be performed on clean simulated waste. The hazard classification determined for the overburden removal demonstration is routinely aceepted by the public.

The most prominent risk to personnel during this demonstration is being in the vicinity of the excavator during operation. It is exiremely important that personnel avold

- Tracks of the excavator, txoth with the machine moving or not moving

- Boom and swing are of the boom

- Swing arc of the excavator chassis

- Bucket-No adjustments or other work shall be performed on the buckel unless the excavator is turned off and operators cab is emply.

NOTE-Everyone onsite will be reminded at each morning's sufely meeting that when the excavator's diesel engine is running, it can move in any direction at any time without warning. Access to the test area will be administratively controlled.

The same precautions should be observed around the bulldoeer, although there will be no testing in progress during its use.

\subsection{Lockout and Tagout}

Lockout and tagout procedures will be followed in accordance with the project specific Environmental, Safety, and Health Plan. These procedures should be followed during any maintenance, repair, or adjustment for all engine or electrical equipment

\subsection{Radiological}

No radioactive waste by-products are generated from the work described in this plan No work will be conducted in a radiation or contaminattion area.

\subsection{Electrical}

The electrical power for the dust collector blower will be provided by a $120 / 240 \mathrm{~V}$ generator. The generator will be tumed on only for the actual nun time required. The laser system operates on replaceable or rechargeable batteries.

\subsection{Dust Inhalation}

Any person working downwind of this system or during other high dust limes will wear a filter mask to prevent excessive dust inhalation.

\subsection{Laser Safety}

The operating level of the laser system used for this demonstration is below the level specified by Occupational Safely and Health Adininistration requiring personal protection. The project specific Environment, Safely, and llealth Plan will provide more information. 


\section{BIBLIOGRAPHY}

Bonnenberg, R. W., R. E. Heard, L. M. Mllam, and L. R. Watson. Burled Waste Inregraled Demonsiration FY.93 Deployment Plan, EOQ.WTD. 10s39. February 1993.

BO\&O Idaho. Inc., Safety Manual.

EO\&O Idaho, Inc., Science and Technology Standard Pracices Manual. 
Appendix A

Detalled Test Procedure

A. 1 


\section{Appendix A}

\section{Detalled Test Procedure}

\section{MOBILIZATION}

1. Set up the particulate air samplers, pump house and generator as shown in Figure 7 of the main report. Ensure proper now rates are being altained and confirm operation of the data loggers and operation of the pump housc. Install soil moisture cells at depths of approximately $3,4,6,12,16$, and 20 in. in an area adjacent to the Cold Test Pit that will not interfere with test operations.

2. Hold safety kick-off mecting at the Cold Test Pit with Radioactive Waste Management Complex (RWMC) safety engincering. Review all precautions and procedures to ensure a safe work site. Ensuring safely equipment is available, and everyone is instructed in its proper use.

3. Review the test plan and sequence of events for the test.

4. Unload and stage all equipment at the site being cautious not to disturb the Cold Test Pit area.

a. Stage the excavator on the cast side of the Cold Test Pit.

b. Connect the hoses and distribution for the dust control system.

c. Connect the low-volume (LO.VOL.) air samplers to the excavator.

d. Set up the generator to the cast side of the excavator and approximately half way down the length of the pit. Connect the power cable to the blower assembly on the excavator.

e. Turn on the generator, power up the blower, and eheck for proper operation.

f. Start the excavator and check out all movements and operations.

g. Confirm that the excavator can rotate as per job requirements without pinching or otherwise damaging the hoses and cable.

h. Confim that all fuel lanks and lubricant levels are full and ready for operation.

5. Using a transit, install the sighting lines at the side and end of the pit to use for locating the depth measurement grid points for the Contour Measurement and Phase II tests.

a. Install the sighting markers as per Figure 6 of the main report for the pit contour measurement

b. Contirm that the grid points as shown in Figure 6 can be casily located and repeated using the markers as visual guides.

6. Set up the laser grade control system.

a. Place the laser transmitter at the approximate location as shown in Figure 6 . Set the height of the transmitter as low as possible to transmit across the top of the crest of the Cold Test Pit without obstruction. Check the self leveling for proper function. Tum on the power and conlim proper operation.

b. Set up the manual graduated mast with the laser receiver. Tum the receiver on and confirm proper operation. 
7. Compleie the contour map of the pit as shown in Figure 6.

a. Use the manual mast to locate each grid point using the sighting markers. Move the laser receiver up or Jown the mast to properly align the receiver to the laser beam.

b. Record the height reading from the mast at that point on the proper form. Repeat this for all 30 locations.

c. The contour measurement is now complete.

8. Using the excavator with the bucket set for a 6-in. cut, remove the high points on the eastem half of the Cold Test Pit to provide a flat datum plane of at least $10 \times 40 \mathrm{ft}$. At the end of each strip, rotate the excavat : $: 180$ degrees and dump the scil being careful to generate as little unnecessary üust as possible.

a. Use the contour height measurements as a guide to determine where the highest point is on the pit.

b. Move the excavator to this area and begin taking cuts to level the area. The laser system is to be used for reference and as a guide determine the location and number of cuts necessary to provide the flat datum plane.

NOTE-It is r ry important that personnel taking readings or other data do not work in the immediatc arf a of the excavator or the swing path of its boom.

9. When the system is shut down for the evenirg or if the wind changes direction, plastic sheets should be laid over the soil dump area to provent contamination of unexcavated pit area.

\section{PHASE I}

1. Mark off the $10 \times 40-\mathrm{ft}$ area for the Phase I test. Set up the sighting lines to the west and south sides of the $p^{i t}$ to use as guides for taking cut depth measurements at all 30 grid locations.

2. Using the Phase I sighting lines as guides and laser transmitter as a flat plane reference, use a laser receiver on a graduated survey mast to establish and record the height readings across the 30 point grid on the proper forms.

3. Set the excavator bucket for a 3-in. cut. Ensure the excavator is turned off, and the operator's cab is empty.

4. Execute the flow program and enter the appropriate program identification. Select display time for flow readout for each sampler and in tiate the . Irogram. Typically, the flow display will readout in increments of 5 seconds. The program shall be set to run for the desired length of time to cover the length of test planned. All flow data shall directly transferred from the data logger to the disk storage in the increments previously described. The program can be terminated at any time to accommodate varying test lengths.

3. Place filters in the high-volume (HI-VOL) samplers, turn on the samplers, and obtain 30 minutes worth of background datu.

6. Turn off the sampler pumps, remove the background sample filters, and place in premarked petri dishes. The petri dishes shall be stored for later analysis.

7. The next set of clean filters are removed from their petri dishes and placed in the air samplers. 
8. Tum on the HI-VOL and LO-VOL samplers and begin taking contamination control data.

9. Start at the south end of the flat datum plane and remove a complete layer from the total datum plane area taking special care when crossing the $10 \times 40$-ft test area.

10. Tum off the sampler pumps, remove the background sample filters, and place in premarked petri dishes. The petri dishes shall be stored for later analysis.

11. Repeat Step 1 to measure the actual soil removed at all 30 points in the $10 \times 40-\mathrm{ft}$ area and establish a datum for the next cut. Record any breaks or steps left at the edges of the cuts. Record this information on the proper forms. The Sonsub project manager or project engineer and the EG\&G Idaho, Inc., site representative will approve these data before proceeding with the test.

12. Set the excavator bucket for a 4-in. cut. Ensure the excavator is turned off and operator's cab is empty.

13. Repeat Steps 4 through 11 but with the excavator bucket set for a 4 -in. cut.

14. Set the excavator bucket for a 6-in. cut. Ensure the excavator is tumed off and operator's cab is empty.

15. Repeat Stef 4 through 11 but with the excavator bucket set for a 6-in. cut.

16. Leave the bucket set at the 6-in. cut setting.

17. Repeat Steps through 11, but take two 6-in. cuts over the total datum plane area to total 12 in. before taking the aciual cut depth readings.

18. Verify that all readings are properly recorded. The Sonsub project manager or project engineer and EG\&G lJaho site representative will approve these data before proceeding with the demonstration.

19. This completes Phase $I$ of the test.

\section{PHASE II}

1. Remove the Phase I test sighting lines and other markers.

2. Using the Phase II sighting lines as guides and the laser transmitter as a flat plane reference, use the manual laser receiver on a graduated survey mast to establish and record the height readings across the 50 point grid required for the Phase II test. Record this information on the proper forms. The Sonsub project manager or project engineer and EG\&G Idaho site representative will approve these data before proceeding with the test.

3. Mark off a $10 \times 10-\mathrm{ft}$ diamond shaped area in the middle of the pit to represent an obstacle to be excavated around.

4. Execute the flow program and enter the appropriate program identification. Select display time for flow readout for each sampler and initiate the program. Typically, the flow display will readout in increments of 5 seconds. The program shall be set to run for the desired length of time to cover the length of test planned. All flow data shall be directly transferred 'rom the data logger to the disk storage in the increments previously described. The program can be terminated at any time to accommodate varying test lengths.

5. Place filters in the HI-VOL samplers, turn on the samplers, and obtain 30 minutes worth of background data. 
6. Turn off the sampler pumps, remove the background sample filters, and place in premarked petri dishes. The petri dishes shall be stored for later analysis.

7. The next set of clean filters are removed from their petri dishes and placed in the air samplers.

8. Set the excavator bucket for a 3,4, or 6-in. cut. Ensure the excavator is turned off and operator's cab is empty. This setting will be used for the remainder of the demonstration. The trailing control plane must be reset to zero after the first cut in each layer.

9. Tum on the HI-VOL and LO-VOL samplers and begin taking contamination control data.

10. Start at the south end of the pit operating from the east side. Begin taking $3 \mathrm{ft}$ wide strips of soil. At the end of each strip, rotate the excavator 180 degrees and dump the soil being careful to generate as little unnecessary dust as possible.

11. As the excavator moves down the length of the pit, a Sonsub technician begins taking actual cut depth measurements at the grid locations. Record any breaks or steps left at the edges of the cuts. Record all measurements on the proper forms. Operation of the excavator must be coordinated with EG\&G Idaho personnel taking air samples. Take at least 10 soil moisture probe readings at rundom locations throughout the area of soil to be removed. The depth at which the reading will be taken shall be one-half of the depth of soil to be removed in the next increment.

NOTE-It is very important that personnel taking readings or other data do not work in the immediate area of the excavator or the swing path of its boom.

12. The Sonsub project manager or project engineer and EG\&G Idaho site representative will approve the data for each layer before proceeding with the test.

13. When the excavator reaches the end of the pit, having completed one pass, it returns to the south end and starts a second pass. Continue taking cuts down to a $6 \mathrm{ft}$ maximum depth or until direction by the EG\&G Idaho site representative.

14. Once sufficient data have been gathered to the satisfaction of the EG\&G Idaho site representative, the Phase II test can be considered complete.

\section{PHASE III}

1. Move the excavator to the western side of the Cold Test Pit to begin the production phase (Phase III) of the demonstration.

2. Take as many cuts as necessary to establish a flat datum on the top of the pit using the laser system as a reference.

3. At the end of each cut, rotate the excavator 180 degrees and dump the soil being careful to generate as little unnecessary dust as possible.

4. Once the flat datum is established, the approximate track pattern required by the excavator to complete a complete layer removal for each test will be recorded. This information will be utilized to determine the area that would be required outside of the perimeter of a hot pit for safely maneuvering an excavator of this size class.

5. Begin taking $3 \mathrm{ft}$ wide slices of soil traversing down the length of the pit and back. The object is to establish a measurable production rate for this process with no delays for sampling or measurements. Record all volume and time data on the proper forms.

6. As the excavator moves down the length of the pit, a Sonsub technician begins taking actual 
cut depth measurements at the grid locations. Record any breaks or steps left at the edges of the cuts. Record all measurements on the proper forms.

7. The Sonsub project manager or project engineer and EG\&G Idaho site representative will approve the data for each layer before proceeding with the test.

\section{COLD TEST PIT RESTORATION}

1. At the completion of this test, remove all markers and other items from the site. Use the bulldozer and excavator to restore the site to an as found condition.

2. Demobilize all equipment and personnel from the site. 

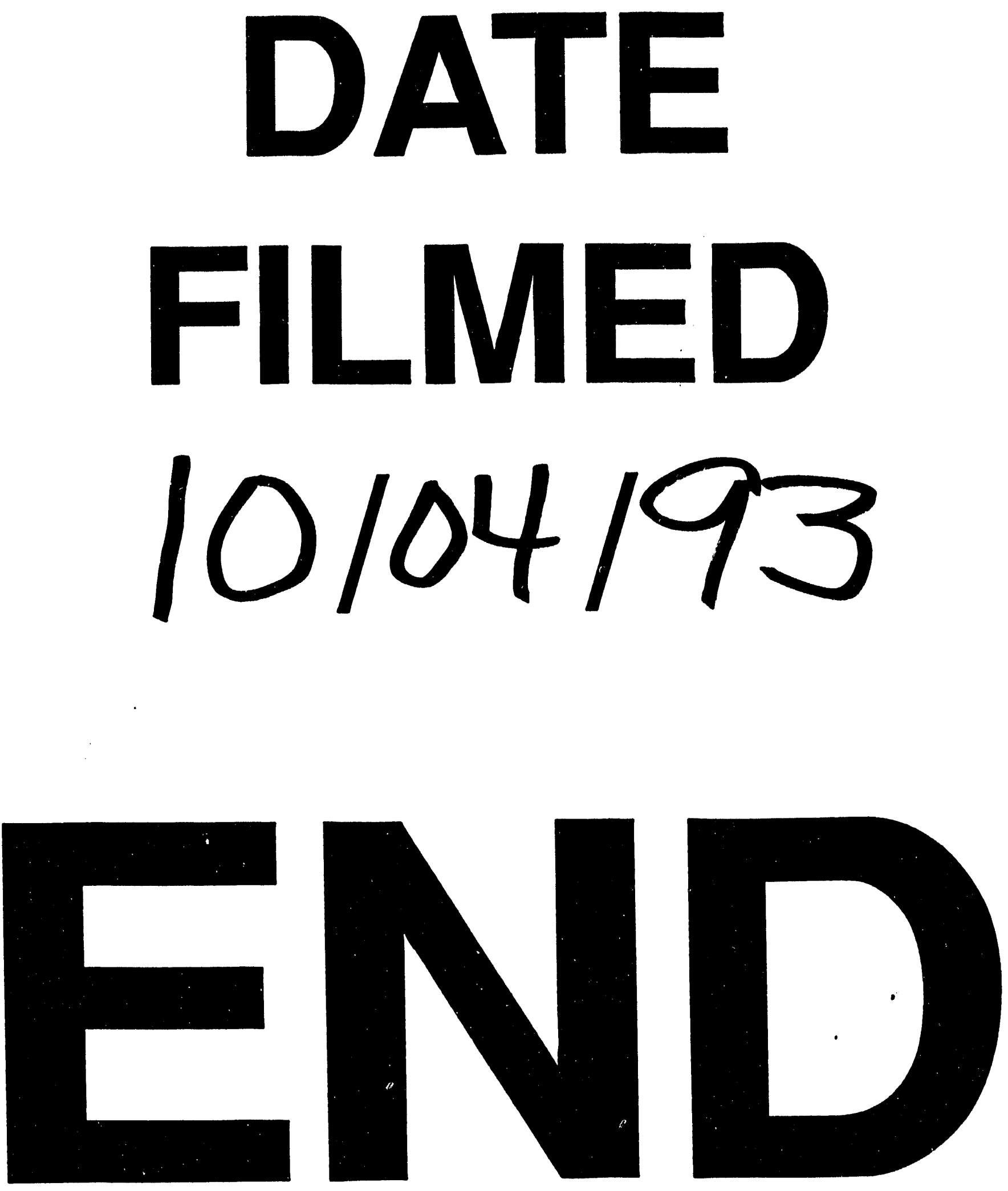


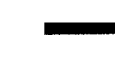

